\title{
Recent progress on electrohydrodynamic nanowire printing
}

\author{
Wenlong $\mathrm{Xu}^{\dagger}$, Shuo Zhang ${ }^{\dagger}$ and Wentao $\mathrm{Xu}^{*}$
}

\begin{abstract}
Electrohydrodynamic nanowire printing (eNWP) technology can be used to print ultra-fine nanowires (NWs) in patterns at high precision. This technology has enabled advances in large-area patterned NWs, high-precision and high-integration devices, nanoelectromechanical systems, and bio-inspired devices. The electrical properties of the devices printed using e-NWP can be adjusted by controlling the gaps and diameters of the NWs. These forms have widespread application in field effect transistors, synaptic mimicry and masks. This review summarizes the basic principles, materials, printing methods and applications of e-NWP, and then outlines the research direction and obstacles that should be overcome to expand the applications of e-NWPs, and enable their commercialization.
\end{abstract}

Keywords: electrohydrodynamic nanowire printing, nanowire array, polymer, oxide nanowires, lithography

\section{INTRODUCTION}

This review focuses on the evolution and application of the electrohydrodynamic nanowire printing (e-NWP) [13]. e-NWP can be used to precisely control the deposition of nanofibers (NFs) for use in printing of flexible electronics, micro-nanosize devices, and biological tissues [1,4-22]. Therefore, the deposition of NFs in orderly arrangements has achieved wide applicability in electrostatic spinning technology [23-74].

The main methods to prepare ordered electrospun NFs include the roller method, the parallel-electrode method, the patterned-electrode method [32] and the near-field electrospinning (nf-ES) method [75-116]. Early development of electrospinning equipments focused mainly on the nozzle and receiver [75,77-81]. To reduce the danger and high energy consumption that are caused by the high voltage of electrostatic spinning, researchers developed low-voltage electrospinning by increasing the auxiliary effect of external forces to reduce the electric field force [75]. Subsequently, the components of spinning liquid components, and the adjuvants were modified to have special properties [76]. Then nf-ES was developed to reduce the spinning distance and therefore the required intensity of electric field [78]. In 2003, a triangular thin film tip was adapted as a spinning tip; this method reduced the spinning distance to $2 \mathrm{~cm}$, and spinning voltage to $3-4 \mathrm{kV}$. This method allows nf-ES at low voltage, and obtains orderly arrangement of microfibers or NFs by rotating a collection plate relative to the tip [75]. nf-ES has been applied to electronic devices, photovoltaics and biology [76-144] (such as human gesture recognition [113], and controlling of cell orientation [114]).

e-NWP was introduced in 2013 [1]; it overcame the demerits of traditional electrospun fibers such as disorder and poor control in position, and realized precise manipulation of single nanowires (NWs). e-NWP allows preparation of highly-ordered polymer NWs, metal doped organic NWs (ONWs) and metal-film NWs on flexible substrates with high efficiency on a large area [8$10,13,17,20]$. By use of e-NWP, the diameter, number and position of NWs can be controlled according to the requirement of the NW array, thus avoiding the need for secondary operations to align the NWs [1,4-22].

Electronic devices based on NWs show high integration, low energy consumption and flexibility [4-6,810,12-18,20]. e-NWP can be used to adjust the electrical properties of the device for applications in field effect transistors (FETs), sensors, memories, and bio-mimetic

Institute of Photoelectronic Thin Film Devices and Technology, Key Laboratory of Photoelectronic Thin Film Devices and Technology of Tianjin, Nankai University, Tianjin 300350, China

† These two authors contributed equally to this work.

* Corresponding author (email: wentao@nankai.edu.cn or bnuch@hotmail.com) 
devices. The electrical properties of the device can be adjusted by controlling the number of printed NWs, and the gap between them. e-NWP has potential applications to fabricate flexible wearable sensors, electronic textiles, transistors and precision integrated circuits.

\section{MECHANISM}

e-NWP technology can realize accurate and controllable printing of NWs or NFs. The basic principle of e-NWP is to convert the printing ink into a straight solidified NW under high electrical field before printing it onto the substrate. The NWs are cylindrical instead of flaky. It is also the difference between e-NWP and electrohydrodynamic jet printing. This goal is achieved by controlling the tip-to-collector distance $\left(d_{(t, c)}\right)$ to $<1 \mathrm{~cm}$, and reducing the voltage of e-NWP [1] (Fig. 1). The NW solidifies before it is printed onto the substrate (Table 1). During e-NWP, the ink flows in a jet from the probe tip, and the printing voltage $\left(V_{\mathrm{p}}\right)$ is about $0.5-3.6 \mathrm{kV}$. A collection plate is placed on a two-dimensional (2D) moving platform, and it is moved under control to realize fixed-point printing of patterns in a plane.

\section{DIFFERENT TYPES NWS AS OBTAINED FROM e-NWP}

Polymers are the best choice for electrospinning materials because of their one-dimensional (1D) linear structure and useful range of properties, such as viscosity, flexibility and strength. Polymer materials that are used in e-NWP include poly(ethylene oxide) (PEO) $[1,17,18]$, poly(4-vinylphenol) (P4VP) [17,22], polyvinyl carbazole (PVK) [16,19], poly(3-hexylthiophene) (P3HT) [10,15] and poly (vinylidenefluoride-co-trifluoroethylene) (PVDF-TrFE)
[9]. According to the requirements of electrospinning, polymers can be used in pure form or in blends.

\section{Pure polymer NWs}

PVK NWs were aligned with PVK styrene solution using e-NWP (Fig. 2) [1]. Fig. 2a shows that PVK NWs not only possess nanoscale dimensions $(290 \mathrm{~nm})$, but also can realize a large-scale high-regularity array; Fig. 2b shows that the PVK NWs have a regular circular cross section. The e-NWP PVK NW can be removed after depositing metal films as a shadow mask to make a channel (Fig. 2 c). In addition, the different diameters of PVK NWs can be attained by adjusting the PVK concentration $(2.93,3.96,4.72,5.71$ or $6.19 \mathrm{wt} \%)$ which follows the scaling relationship $\left(D \sim \rho^{1.68}\right)$. The diameter of PVK NW is $290 \mathrm{~nm}$. The scaling relationship in e-NWP is consistent with the relationship of the conventional electrospinning method $\left(D \propto \rho^{\delta}\right)$. Other polymers can be printed by e-NWP using a suitable solution, such as (1) aligned PVK NWs using PVK styrene solution (Fig. 2) [1]; (2) PVDF-TrFE (75:25, Solvay) (15 wt\%) dissolved in a solvent mixture of $\mathrm{N}, \mathrm{N}$-dimethylformamide (DMF) and tetrahydrofuran (THF) $\left(w: w=1: 4, V_{\mathrm{p}}=1.1 \mathrm{kV}, d_{(\mathrm{t}, \mathrm{c})}=\right.$ $7 \mathrm{~mm}$ ) [9]; (3) $30 \mathrm{wt} \% \mathrm{P} 4 \mathrm{VP}$ in dimethylformamide/ ethanol solution $\left(w: w=60: 0, V_{\mathrm{p}}=1.4 \mathrm{kV}, d_{(\mathrm{t}, \mathrm{c})}=7 \mathrm{~mm}\right)$ [8]; and (4) P3HT/toluene solutions $\left(0.2,2\right.$, and $5 \mathrm{wt} \%, V_{\mathrm{p}}$ $\left.=1.8 \mathrm{kV}, d_{(\mathrm{t}, \mathrm{c})}=1 \mathrm{~mm}\right)[22]$.

\section{Blended polymer NWs}

Compared with pure polymers, blended polymers have the electrostatic interaction between two blended components. This can make impossible-to-print polymers be printed into NWs by adjusting viscosity and surface

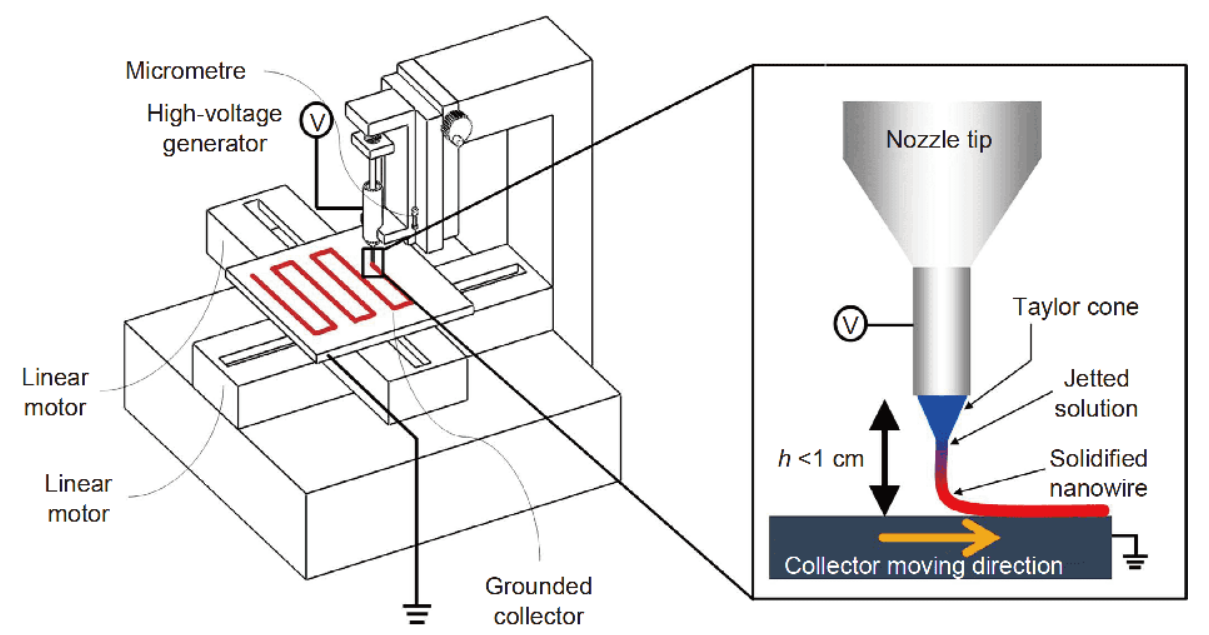

Figure 1 Diagram of electrohydrodynamic nanowire printing setup. Reprinted with permission from Ref. [1]. Copyright 2013, Springer Nature. 
Table 1 Parameters of printing methods, and quality of results

\begin{tabular}{ccccc}
\hline Method & $d_{(\mathrm{t}, \mathrm{c})}(\mathrm{cm})$ & $V_{\mathrm{p}}(\mathrm{kV})$ & Homogeneity & Accuracy \\
\hline ES & $\geq 10$ & $\geq 10$ & Bad & Bad \\
nf-ES & $\leq 2$ & $3-4$ & Excellent & Good \\
e-NWP & $\leq 1$ & $0.5-3.6$ & Excellent & Excellent \\
\hline
\end{tabular}
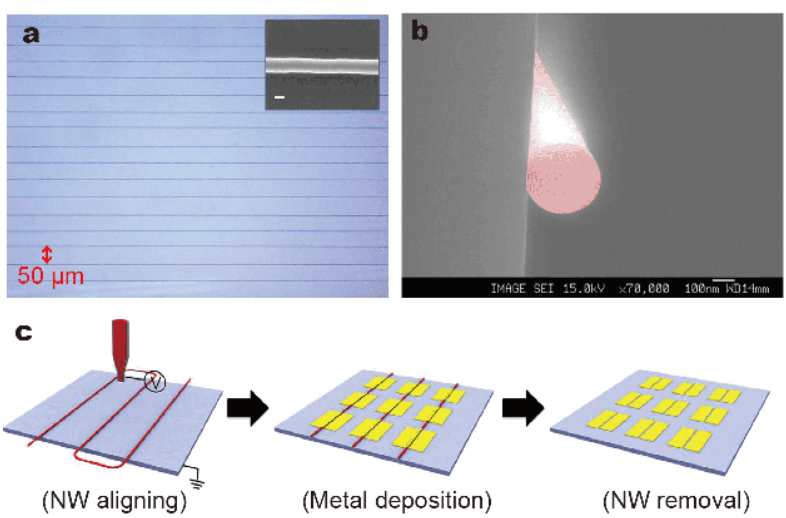

Figure 2 (a) Optical micrograph of well-aligned PVK NWs. (200 nm, scale bar); (b) field emission scanning electron microscopy (FESEM) image showing cross section of well-aligned PVK NW, which forms a perfect circle; (c) schematic illustration of the process for ONW lithography. Reprinted with permission from Ref. [1]. Copyright 2013, Springer Nature.

tension. The electronic properties of blended-polymer NWs can also have more versatility to be adjusted according to needs. Large-area poly $\{[N, N$-bis $(2$-octyldodecyl)-naphthalene-1,4,5,8-bis(dicarboximide)-2,6-diyl]-alt5,5-(2,2-bithiophene)\} (N2200):PEO-blend NW ( $w: w=$ 7:3) arrays were printed using a high-speed e-NWP, from a blend of N2200 and PEO in trichloroethylene and chlorobenzene cosolvents [1]. e-NWP has been used to print organic polymers in various configurations. Coresheath-structured $\mathrm{P} 3 \mathrm{HT} / \mathrm{PEO}$ NWs have been prepared using blends of P3HT/PEO 70:30 ( $w / w)$ [18]. Highlyaligned P3HT NWs doped with 2,3,5,6-tetrafluoro7,7,8,8-tetracyanoquinodimethane (F4-TCNQ) have been achieved $\left(V_{\mathrm{p}}=1.5-2 \mathrm{kV}, d_{(\mathrm{t}, \mathrm{c})}=7 \mathrm{~mm}\right)$ [15]. Patterned nano-scaled structures of polyvinylpyrrolidone (PVP), PEO and tetracycline hydrochloride composites have been printed [11]. PEDOT:PSS-PEO composites were printed by adding $1 w / v \%$ PEO directly to conductive PEDOT:PSS solution (1.0 wt\% in water) to create PEDOT:PSS-PEO solution [7]. Furthermore, thiophene diketopyrrolopyrrole (FT4-DPP):PEO NWs have been achieved by printing FT4-DPP:PEO (7:3, w:w)/chloroform solution (Fig. 3) [5]. These methods achieved the printed NWs of blending polymer, and broadened the

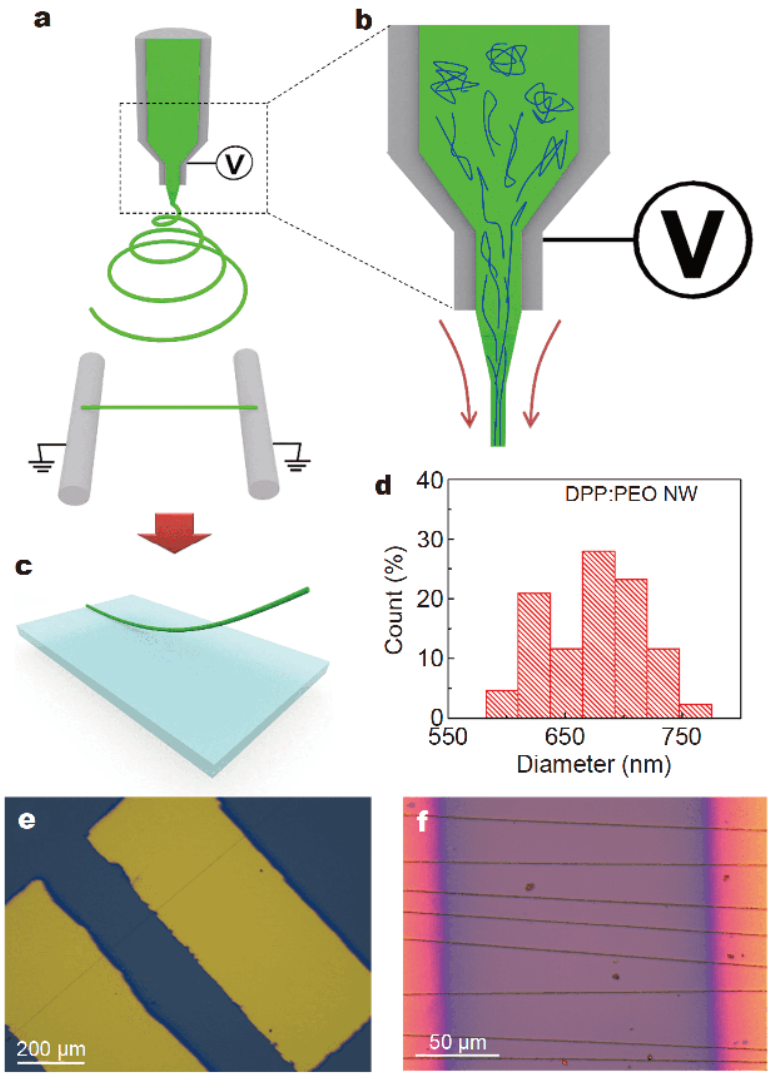

Figure 3 Fabrication of aligned (FT4-DPP):PEO NWs. (a) Schematic illustration of electrospinning of aligned (FT4-DPP):PEO NWs between parallel electrodes. (b) Polymer chain alignment during polymer solution jetting by high-electric-field and strong shear force. (c) Schematic illustration of transfer process of single aligned (FT4-DPP):PEO NW onto the substrate. (d) Histogram of diameter distribution of (FT4DPP):PEO NW. Optical images of FETs on $\mathrm{SiO}_{2} / \mathrm{Si}$ substrate and Au S/ D electrode with (e) single and (f) multiple (FT4-DPP):PEO NWs. Reprinted with permission from Ref. [5]. Copyright 2018, John Wiley and Sons.

range of e-NWP materials.

\section{Metallic NWs}

$\mathrm{Cu}$ NFs can be produced by adding PVP and $\mathrm{Cu}$ (II) trifluoroacetate to a mixture of DMF and THF solvents [20]. Printing of $\mathrm{PVP} /\left(\mathrm{Cu}\left(\mathrm{CO}_{2} \mathrm{CF}_{3}\right)_{2}\right)$ composite NF array by eNWP on the substrate (Fig. 4), followed by calcination in air at $500^{\circ} \mathrm{C}$ for $1 \mathrm{~h}$, then calcination in $\mathrm{H}_{2}$ at $300^{\circ} \mathrm{C}$ for $1 \mathrm{~h}$ yielded the $\mathrm{Cu} \mathrm{NF}$ array. The average diameter of $\mathrm{Cu}$ $\mathrm{NF}$ was $710 \pm 90 \mathrm{~nm}$. The energy-dispersive X-ray spectroscopy (EDS) spectrum (Fig. $4 \mathrm{~b}-\mathrm{d}$ ) showed that polymer and precursor were decomposed after the calcination at $500^{\circ} \mathrm{C}$ in air, and the $\mathrm{CuO} \mathrm{NFs}$ were reduced to $\mathrm{Cu}$ NFs at $500^{\circ} \mathrm{C}$ in $\mathrm{H}_{2}$. Aligned composite NFs with constant spacing of $100 \mu \mathrm{m}$ were shown in Fig. 4d. Parallel and 

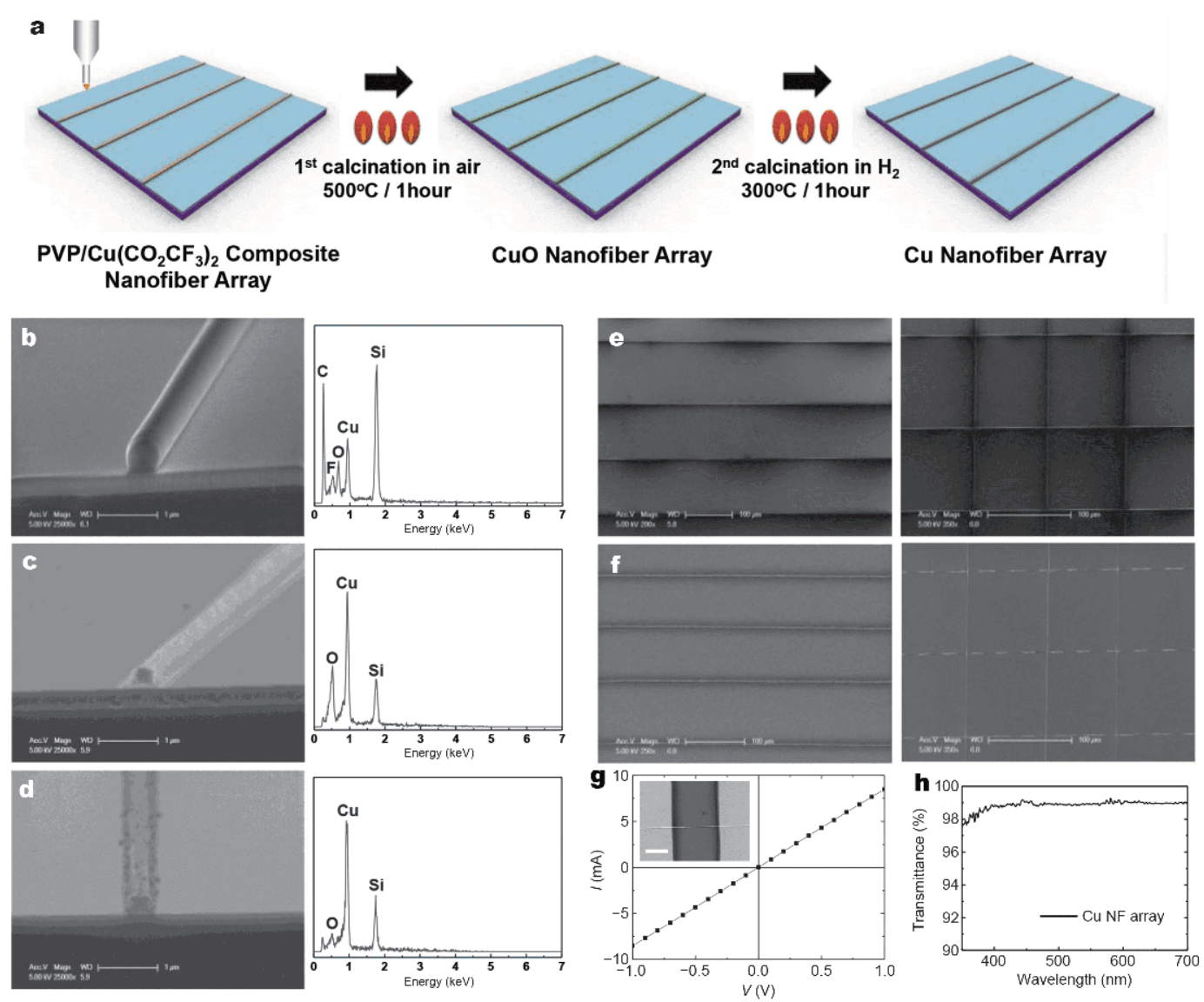

Figure 4 (a) Process to print $\mathrm{CuO}$ NF and Cu NF array with polymer and ink composed of a solution of metal precursors. SEM images and EDS spectra of (b) a PVP/Cu( $\left.\mathrm{CO}_{2} \mathrm{CF}_{3}\right)_{2}$ composite NF, (c) a CuO NF, and (d) a Cu NF (1 $\mu \mathrm{m}$, scale bar). SEM images of parallel and perpendicular patterns of (e) PVP/Cu( $\left.\mathrm{CO}_{2} \mathrm{CF}_{3}\right)_{2}$ composite NF and (f) $\mathrm{Cu}$ NF $(100 \mu \mathrm{m}$, scale bar). (g) Current-voltage $(I-V)$ curve of single Cu NF aligned between two gold electrodes with a gap of $100 \mu \mathrm{m}$ (an SEM image of the electrodes/nanofiber is shown in the inset; scale bar: $50 \mu \mathrm{m}$ ). (h) UV-vis spectrum of parallel patterns of $\mathrm{Cu}$ NF array on the glass substrate. Reprinted with permission from Ref. [20]. Copyright 2014, John Wiley and Sons.

perpendicular patterns of $\mathrm{Cu} \mathrm{NF}$ arrays were achieved (Fig. 4f). It shows that resistivity of e-NWP Cu NF (14.1 $\mu \Omega \mathrm{cm})$ is lower than that of the previously reported electrospun $\mathrm{Cu}$ NF $(120 \mu \Omega \mathrm{cm})$ (Fig. 4g). The parallel patterns of $\mathrm{Cu}$ NF array on the glass show more than $98 \%$ transmittance in the visible range (Fig. $4 \mathrm{~h}$ ). This method achieved the printed transparent NWs of $\mathrm{Cu}$ oxide or $\mathrm{Cu}$, and broadened the range of e-NWP materials.

e-NWP can also produce long Type III Ag NWs (Fig. 5) [10] without breaks by using a strong electric field to jet a highly viscous PVP and metal precursors from the syringe. Low resistivity $(\rho=5.7 \mu \Omega \mathrm{cm})$, low sheet resistance $\left(R_{\mathrm{S}} \approx 26.9 \Omega \mathrm{sq}^{-1}\right)$ and high transmittance $(T>92 \%$, in visible range) of e-NWP Ag NWs with an average diameter of $695 \mathrm{~nm}$ were shown in Fig. 5d-g. The polymer and metal precursors solidify into composite NWs by evaporation. The composite NWs become Ag NWs after calcination from PVP with the $\mathrm{CuO}$ frame structure. It is an improved method which avoids the use of $\mathrm{H}_{2}$ gas in the reduction process.

Al-NF electrodes can be produced by lithography around PVK NFs mask [13] (Fig. 6). The interfiber separation $(70 \mu \mathrm{m})$ and the average diameter (1.11 \pm $0.12 \mu \mathrm{m}$ ) of PVK NF was shown in Fig. 6b, c. The fibers can separate the Al layer very effectively by depositing $40 \mathrm{~nm} \mathrm{Al}$ on the PVK NFs arrays (Fig. 6d). The fiber pixel separators can be detached by the taping method (Fig. 6f, g). This work suggests that e-NWP can be used to fabricate highly aligned organic NF arrays to pattern organic light-emitting diodes (OLEDs).

Similarly, Au-plated NWs were prepared by depositing an Au layer on P4VP NWs [8] (Fig. 7). First, Au nanoparticles were produced by the vapor of hydrazine monohydrate. Then Au precursor was adsorbed to the P4VP NW surface by electrostatic interaction after (1) complexation, (2) reduction, and (3) coarsening at room 

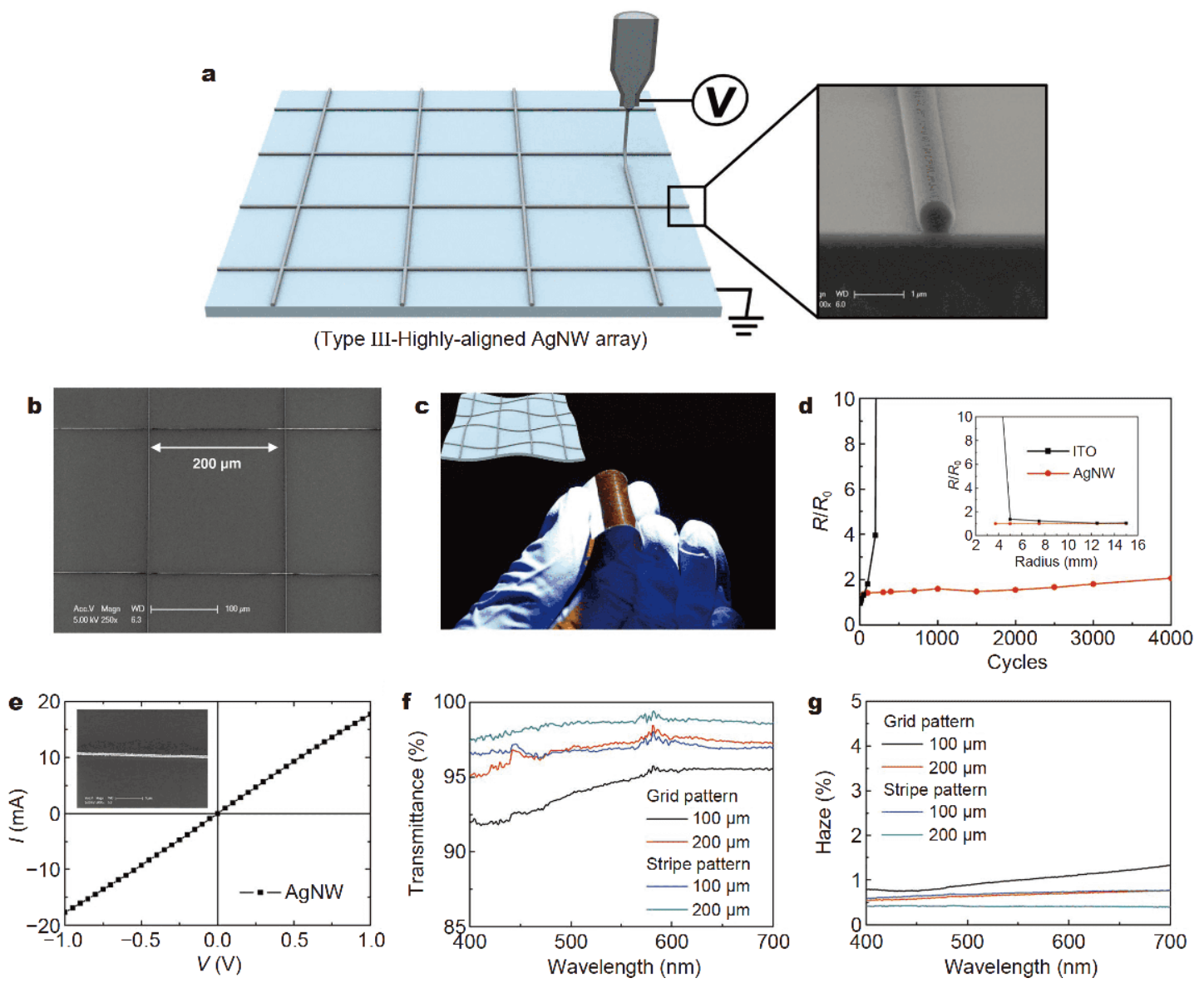

Figure 5 (a) Simulation diagram of the printing process of Type III-highly-aligned Ag NWs array with polymer and metal precursors mixed solution ink and SEM image of the composite NW; (b) SEM images of grid-patterned Ag NW arrays (100 $\mu \mathrm{m}$, scale bar); (c) digital image of Ag NW array on flexible polyimide film. (d) Bending stability of AgNW/PI and indium tin oxide (ITO)/polyethylene terephthalate (PET) against bending cycles (inset: $R_{\mathrm{S}} v s$. bending radius of AgNW array and ITO). (e) $I-V$ curve of Ag NW. (f) Optical transmittance and (g) haze characteristics of Ag NW arrays with different patterns and pitch size in the visible range. Reprinted with permission from Ref. [10]. Copyright 2016, John Wiley and Sons.
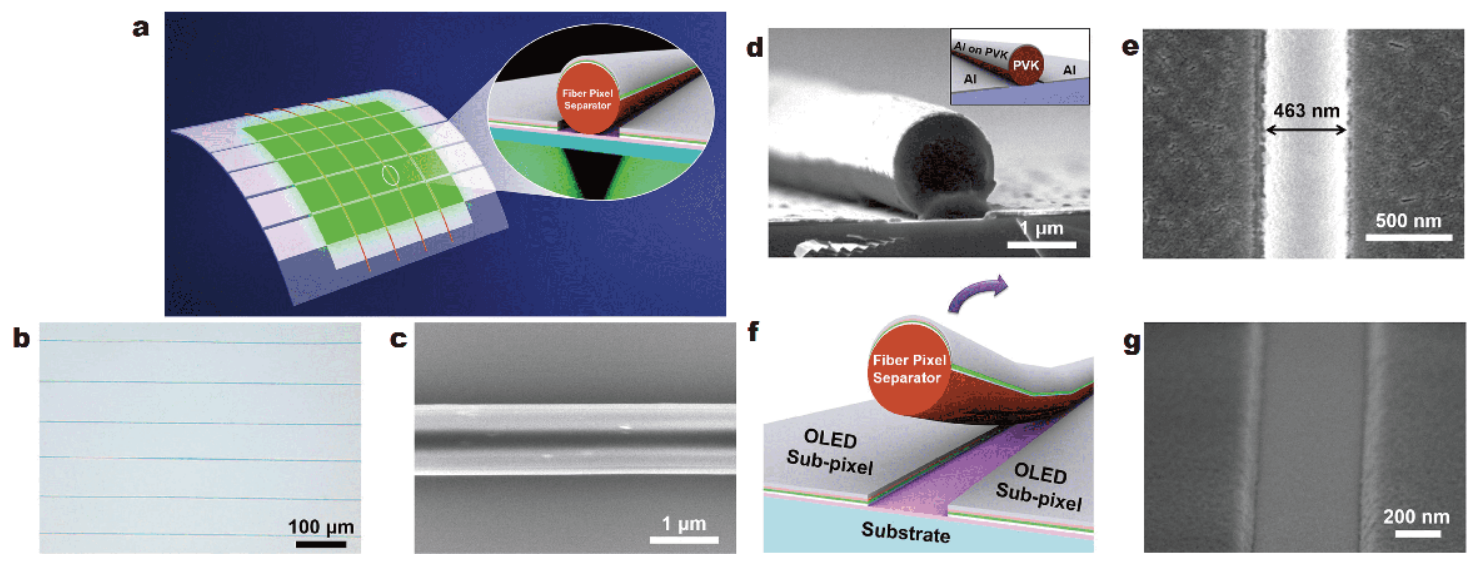

Figure 6 (a) Schematic illustration of Al NF pixel separators in OLEDs. (b) Optical micrograph of a PVK NF array with $70 \mu \mathrm{m}$ interfiber separation. (c) SEM image of a PVK NF with diameter of $1.01 \mu \mathrm{m}$. (d) Cross-sectional SEM image of PVK NFs on which $40 \mathrm{~nm}$ thick $\mathrm{Al}$ was deposited. Inset is a schematic illustration of the SEM image. (e) SEM image of a PVK NF on which $170 \mathrm{~nm}$ thick LiF was deposited. (f) Schematic illustration showing the principle of e-NWP. (g) SEM image of separated LiF layer after removing the PVK NF. Reprinted with permission from Ref. [13]. Copyright 2016, John Wiley and Sons. 
temperature. The total resistance followed the behavior of parallel resistors (Fig. $7 \mathrm{~b}$ ). The optical transmittance of parallel patterned $\mathrm{Au} \mathrm{NW}$ arrays with different wire spacing showed that the Au array can be used as a transparent electrode (Fig. 7c). This work suggests that metallic NWs can be used as flexible nanoelectrodes (NEs) by e-NWP and metallization process on a flexible plastic substrate at room temperature. An Au NW electrode array can be produced at room temperature by using these aligned P4VP NW templates [8]. Pure metal precursors cannot be printed using e-NWP, but it is possible with selected polymer benders. The metal precursors can then be printed together with the polymer, which can be removed later through further calcination and reduction processes to remain pure metallic NWs.

\section{APPLICATIONS OF e-NWP PRINTED NANOWIRES}

\section{Field-effect transistor}

The effect of annealing on the regularity of F4-TCNQ/ P3HT NW was shown in Fig. 8a, b [15]. After the in- corporation of F4-TCNQ in P3HT, the two molecular chains aggregated due to the strong electrostatic interaction between the F4-TCNQ and the P3HT chain. The F4-TCNQ molecule has great rigidity, but at high temperature, the $\mathrm{P} 3 \mathrm{HT}$ chain was oriented rapidly. The P3HT chains were confined in the core structure and the PEO sheath in the internal structure of NW before annealing was more regular along the axis, which enhanced the charge transfer. The FETs of undoped P3HT and F4TCNQ/P3HT NW showed typical behavior of p-type organic FETs (Fig. 8c, d). With the increase of the ratio of F4-TCNQ, the maximum on-current and field effect mobility $\left(\mu_{\mathrm{FET}}\right)$ of FET increased (Fig. 8e).

However, the properties of doped FET before thermal annealing was not excellent. The performance of P3HT NW FET doped with F4-TCNQ before annealing was even lower than that of undoped P3HT NW devices. On the contrary, the device performance of annealed doped P3HT NW FET was significantly improved. After thermal annealing at $200^{\circ} \mathrm{C}$, the on-current and the $\mu_{\mathrm{FET}}$ incidentally increased by tens of times $\left(\mu_{\mathrm{FET}}=9.78 \times\right.$ $10^{-3} \mathrm{~cm}^{2} \mathrm{~V}^{-1} \mathrm{~s}^{-1}$ ) compared with that before annealing.
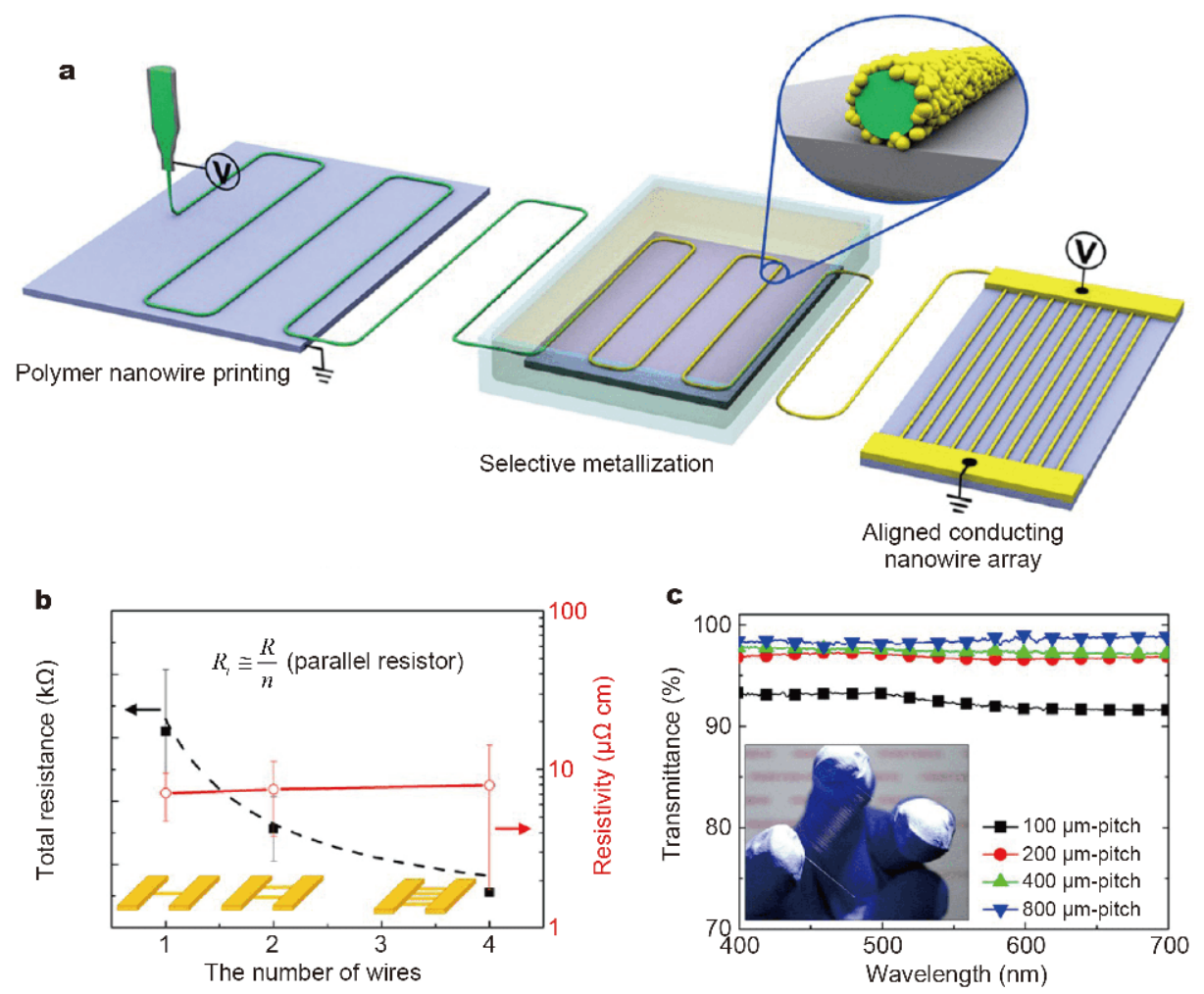

Figure 7 (a) Schematic illustration of the process to prepare a well-aligned template NW array and the electroless Au plating procedure on P4VP NW. (b) Total resistance and resistivity of electroless plated Au NWs with different numbers of wires. (c) Optical transmittance of Au NW arrays with different wire spacing. Reprinted with permission from Ref. [8]. Copyright 2017, American Chemical Society. 


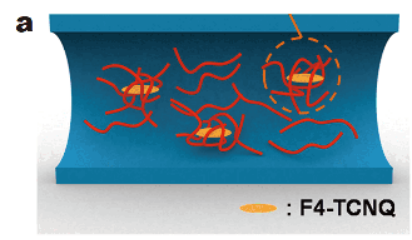

(Before annealing)
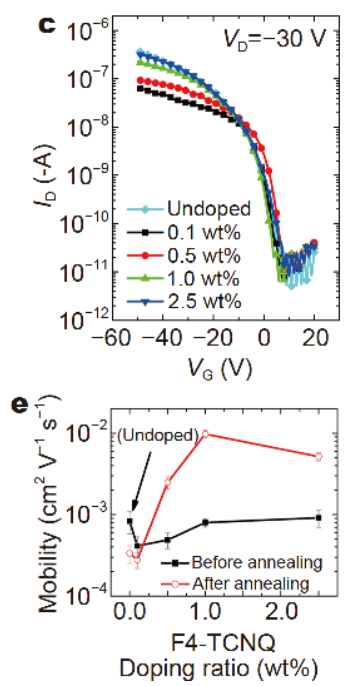

Figure 8 Schematic illustration of the microstructure change of P3HT/ FT4-DPP chain with thermal annealing: (a) before and (b) after annealing. Transfer characteristics $\left(I_{\mathrm{D}}-V_{\mathrm{G}}\right)$ of F4-TCNQ/P3HT NW FET with various concentrations (c) before and (d) after thermal annealing at $200^{\circ} \mathrm{C}$ for $1 \mathrm{~h}$. (e) $\mu_{\mathrm{FET}}$ of F4-TCNQ/P3HT NW FETs before (black line) and after (red line) annealing. (f) $\mu_{\mathrm{FET}}$ (black line) and maximum oncurrents (red line) of F4-TCNQ/P3HT NW FETs with different annealing temperatures. Reprinted with permission from Ref. [15]. Copyright 2017, American Chemical Society.

These results were also consistent with the annealing temperature dependence of electrical properties in F4TCNQ/P3HT NW FETs. With annealing temperature increasing by $100,150,200^{\circ} \mathrm{C}$ in P3HT NW FET doped with $1 \mathrm{wt} \% \mathrm{~F} 4-\mathrm{TCNQ}$, the maximum on-current level and maximum $\mu_{\mathrm{FET}}$ of doped NW FET increased (Fig. 8f).

FETs obtained using e-NWP printed with different materials showed reasonable properties of carrier mobility, contact resistivity and ON/OFF ratio (Table 2). P3HT-PEO NW FET showed the highest carrier mobility of $9.7 \mathrm{~cm}^{2} \mathrm{~V}^{-1} \mathrm{~s}^{-1}$ and very low contact resistivity of $5.53 \Omega \mathrm{cm}$, but ON/OFF ratio $\left(1.38 \times 10^{5}\right)$, whereas metal-based NW FETs had ON/OFF ratio on the order of 10 [8] (Table 2).

Complementary inverter was fabricated by aligning well-parallel P3HT/PEO NWs and N2200/PEO NWs array on the shape-specific $\mathrm{Ti} / \mathrm{Au}$ electrodes with length of $50 \mathrm{~mm}$ on a Si/SiO${ }_{2}(100 \mathrm{~nm})$ substrate (Fig. $9 \mathrm{a}, \mathrm{c}$ and e) [1]. The continuous switching action of the P3HT/N2200 NW complementary inverters is also shown, which is directly related to the parasitic capacitance and resistance of the devices. The average transfer delay of the P3HT/ N2200 NW inverters was almost $1 \mathrm{~ms}$, and a countermirrored voltage characteristics of the inverters were obtained by the source measurement tool. In addition, the complementary inverter showed the typical switching characteristic with gain of $\sim 17$ (Fig. 9d). Compared with other methods, e-NWP can print long, continuous and digitally aligned NWs in one step, without secondary processing. Secondly, the diameter of NWs can be controlled by solution concentration and viscosity, which is an easier process than EBL, and other traditional lithographic techniques.

\section{Ferroelectric memory}

Non-volatile polymer memory has been achieved by using high-throughput direct e-NWP [18]. Polymer semiconducting P3HT:PEO (70:30, w/w) NWs channel

Table 2 Field-effect transistor properties of NWs printed with different materials by e-NWP

\begin{tabular}{|c|c|c|c|c|}
\hline Material of NW & $\begin{array}{l}\text { Carrier mobility } \\
\left(\mathrm{cm}^{2} \mathrm{~V}^{-1} \mathrm{~s}^{-1}\right)\end{array}$ & $\begin{array}{c}\text { Contact resistivity } \\
(\Omega \mathrm{cm})\end{array}$ & ON/OFF ratio & Ref. \\
\hline P3HT-PEO & 9.7 & 5.53 & $1.38 \times 10^{5}$ & [1] \\
\hline FT4-DPP:PEO & $7.46 \pm 0.53$ & - & - & {$[5]$} \\
\hline $\mathrm{P} 4 \mathrm{VP}-\mathrm{Au}$ & $3.5 \pm 1.0$ & 24.8 & - & {$[8]$} \\
\hline PVDF-TrFE-Ag & 0.67 & - & - & [9] \\
\hline P3HT-PEO:Cu,Ag & $5.49 \pm 1.47$ & $7.9 \times 10^{4}$ & $5.93 \times 10^{8}$ & {$[10]$} \\
\hline P3HT-F4-TCNQ & 0.00800 & - & $2.48 \times 10^{4}$ & {$[15]$} \\
\hline P3HT-F4-TCNQ (after annealing) & 0.00978 & - & $1.28 \times 10^{5}$ & {$[15]$} \\
\hline P3HT & 0.008 & - & $1.6 \times 10^{3}$ & {$[22]$} \\
\hline $\begin{array}{c}\text { P3HT } \\
\text { (ODTS surface) }\end{array}$ & 0.045 & - & $2.1 \times 10^{4}$ & {$[22]$} \\
\hline
\end{tabular}


a

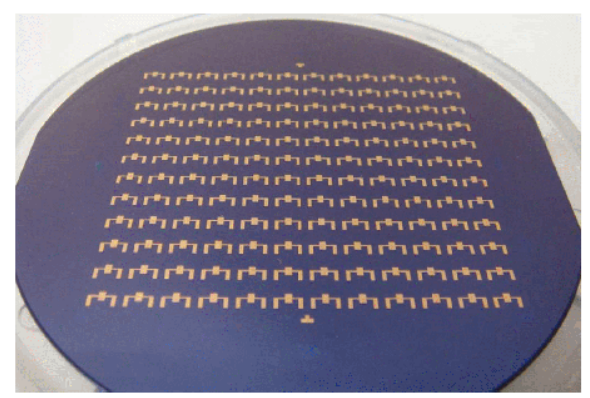

c

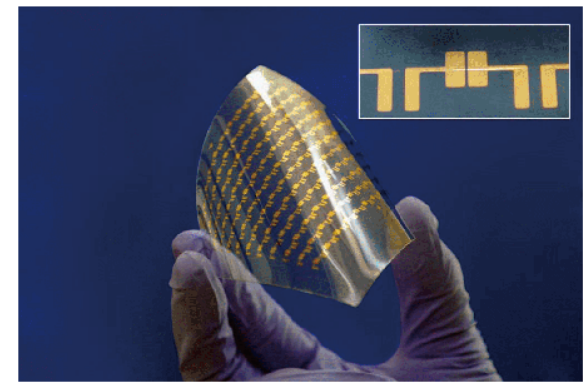

b

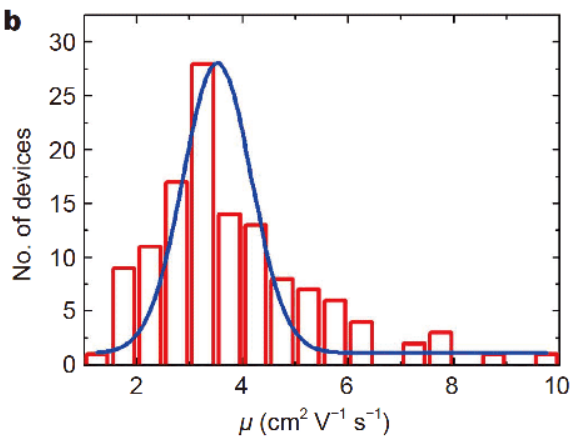

d

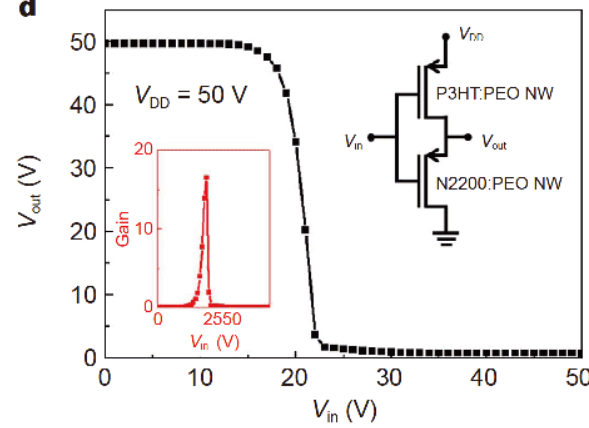

$\mathbf{e}$

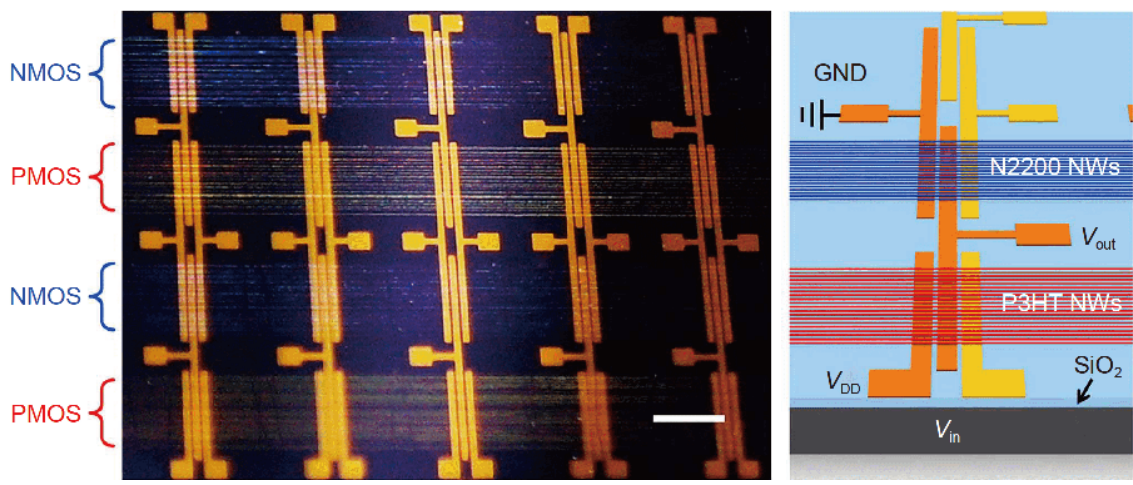

Figure 9 (a) Large-area single P3HT:PEO-blend $(70: 30, w / w)$ NW FET array $(7 \mathrm{~cm} \times 7 \mathrm{~cm})$ with $\sim 300 \mathrm{~nm}$ channel length (144 bottom-contact devices). (b) Histogram of the mobility for large-area P3HT:PEO-blend NW FET array with an average of $3.8 \pm 1.6 \mathrm{~cm}^{2} \mathrm{~V}^{-1} \mathrm{~s}^{-1}$. (c) Large-area single P3HT:PEO-blend NW FET array on polyarylate (PAR) substrate. (d) Input-output voltage characteristic for complementary inverter circuit based on P3HT/PEO NWs and N2200/PEO NWs (inset: gain characteristics). (e) Optical image of inverter array (left, scale bar, $2 \mathrm{~mm}$ ) and schematic illustration of an inverter (right) Ref. [1]. Reprinted with permission from [1]. Copyright 2013, Springer Nature.

and ferroelectric (PVDF-TrFE) insulator were aligned in the polymer memory. The distribution of both ON current values and ON/OFF ratios was calculated. The devices had distinct bistable $\mathrm{ON}$ and OFF current states for memory operation, and the depleted state of $\mathrm{P} 3 \mathrm{HT}$ channel was retained after a positive gate voltage was removed. To control the memory properties, the number and location of wires can be adjusted (Fig. 10d, e). The device with 16 wires had ON/OFF ratio $>100$, which was sufficient for non-volatile memory operation. The memory showed characteristic current hysteresis $>10^{4} \mathrm{~s}$
(Fig. 10f) and write-erase endurance for 120 cycles (Fig. 10g). The flexible polymer NW memory device tolerated $>1000$ bending cycles to a bending radius of $5.8 \mathrm{~mm}$. This work creates a highly flexible and nonvolatile memory. The performance of memory can be controlled by adjusting the number and position of eNWP NWs.

\section{Masks}

In order to build a nanoscale channel in an FET, e-NWP with a maximum speed of $1 \mathrm{~m} / \mathrm{s}$ was used to print well- 

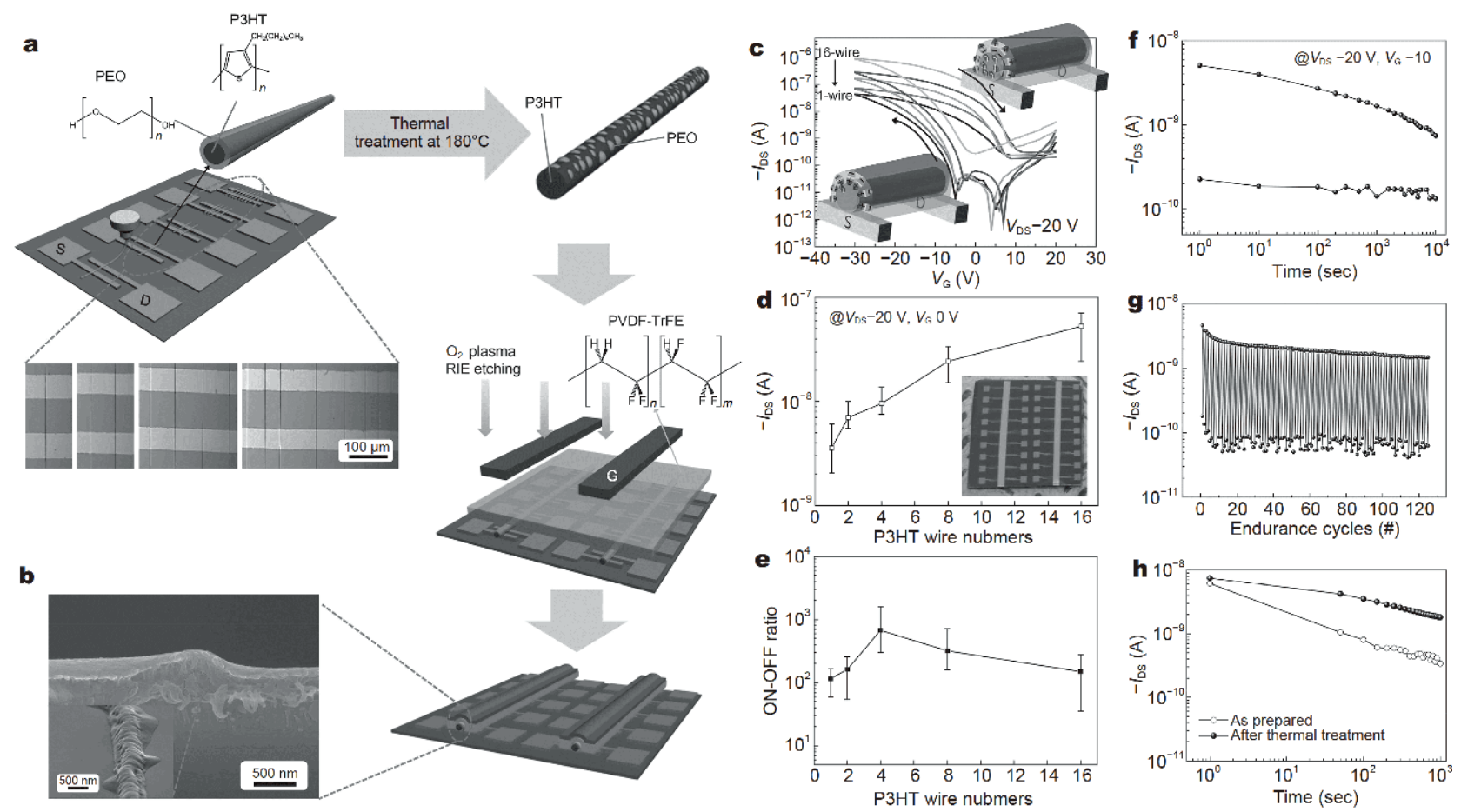

Figure 10 (a) The e-NWP fabrication process of ferroelectric memory with polymer semiconducting NW. (b) SEM images of thermally-treated P3HT $\mathrm{NW}$ on the $\mathrm{SiO}_{2}$ substrate. (c) $I_{\mathrm{DS}}-V_{\mathrm{G}}$ transfer curves of the device demonstrate current hysteresis that arises from non-volatile ferroelectric polarization of the PVDF-TrFE layer. (d) ON current and (e) ON/OFF ratios of devices with different number of polymer wires. (f) Time-dependent retention characteristics and (g) write/erase endurance cycles of $I_{\mathrm{DS}}$ in a polymer NW Fe-FET. (h) Retention data of ON current of NW Fe-FET before and after thermal treatment of polymer NW. Reprinted with permission from Ref. [18]. Copyright 2014, John Wiley and Sons.

aligned PVK NW as a shadow mask under the metal films [1]. The PVK NWs were printed on the substrate and coated with metal film deposited through thermal evaporation. Finally, the PVK NW was removed by ultrasonic treatment to leave nano-gap (Fig. 11). Different channel lengths can be achieved by adjusting the concentration of PVK solution. Even using small radius organic semiconductor NWs (P3HT/PEO NWs) as the channel can be achieved high carrier mobility $\left(9.7 \mathrm{~cm}^{2} \mathrm{~V}^{-1} \mathrm{~s}^{-1}\right)$ and low contact resistivity $(5.53 \Omega \mathrm{cm})$. Channels fabricated in this manner can have nanometerscale lengths, and the length can be adjusted by the width of the NWs. Uniform channels can be obtained using the NW arrays as lithography masks.

A position-customizable and normal-temperature processable metallic NW electrode array was fabricated using aligned ONW templates (Fig. 12) [8]. First, $\mathrm{AuCl}^{4-}$ was selectively adsorbed onto a P4VP NW surface due to the electrostatic interaction between metal-based anions and the protonated pyridyl of P4VP NW surface. Then the $\mathrm{AuCl}^{4-}$ was reduced chemically using hydrazine hydrate vapor $\left(\mathrm{N}_{2} \mathrm{H}_{4} \cdot \mathrm{H}_{2} \mathrm{O}\right)$ to yield elemental $\mathrm{Au}$ nanoclusters or nanoparticles, which were deposited on the P4VP NW array by coarsening. The Au nanoparticles provided nucleation sites and acted as catalysts for metal plating during the coarsening process. Consequently, an $\mathrm{Au}-$ plated NW array that had sufficient density was attained by electrical percolation. The resulting well-controlled thin metal sheath with polymer core has the advantages of very low resistivity of $7.5 \mu \Omega \mathrm{cm}$, high optical transmittance (>90\%), and tolerance of bending. Compared with other lithography techniques, this approach produces nanoscale channels without high-vacuum process.

e-NWP can be used to fabricate arrays of 1D Ag NEs [9] (Fig. 13a). A highly-conductive $\mathrm{Ti}(3 \mathrm{~nm}) / \mathrm{Ag}$ thin layer $(100 \mathrm{~nm})$ was evaporated onto $\mathrm{SiO}_{2}(100 \mathrm{~nm}) / \mathrm{Si}$ substrate, then a precisely-controlled mask that was composed of a PVDF-TrFE ONW array was printed onto the $\mathrm{Ti} / \mathrm{Ag}$ thin layer by e-ONW printing. Various patterns of NWs were easily obtained by adjusting the e-ONW printer's parameters such as printing speed, direction and location (Fig. 13b, c, d). To increase the contact area between NW and Ag film, THF vapor was used to collapse the PVDF-TrFE NW, then the complex was annealed at $45^{\circ} \mathrm{C}$. A cosolvent of $\mathrm{NH}_{4} \mathrm{OH}, \mathrm{H}_{2} \mathrm{O}_{2}$ and $\mathrm{CH}_{3} \mathrm{OH}$ was used to chemically etch the areas of the Ti/ 

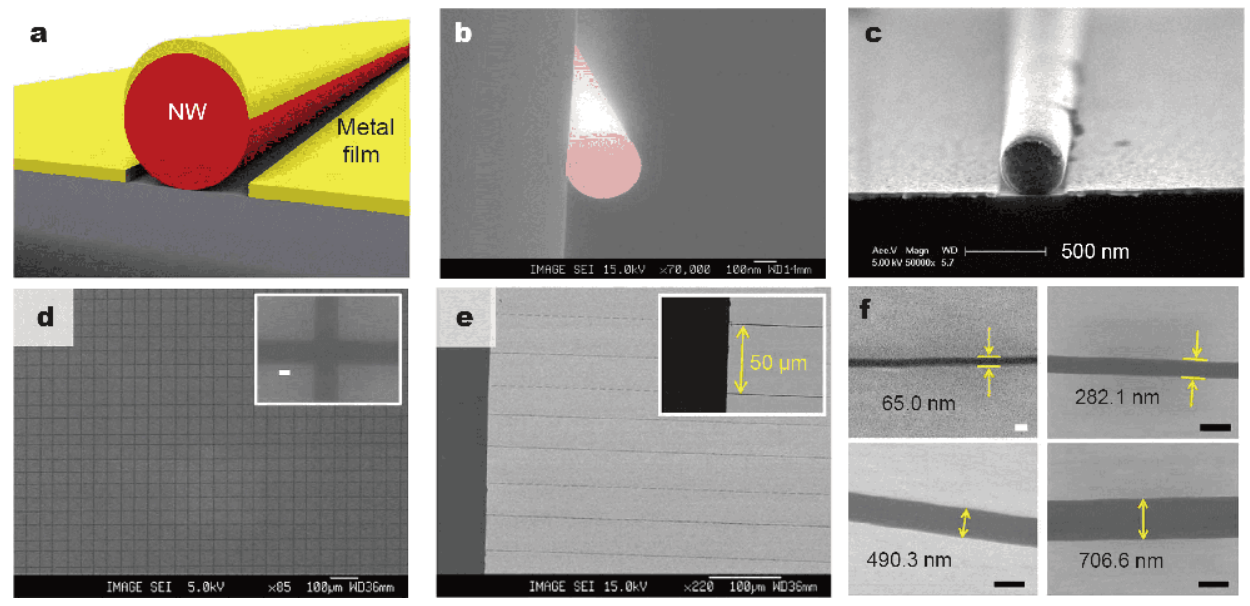

Figure 11 (a) Schematic illustration of an ONW after metal deposition process in e-NWP. FESEM images of cross section of an ONW (b) before, which show a perfect cylinder, and (c) after metal deposition process. (d) Corresponding grid-structured pattern of gold nano-gap (inset: region of intersection, scale bar, $200 \mathrm{~nm}$ ). (e) Parallel array of nano-sized gold gap with 50-mm spacing. (f) Size of gold gap can be controlled by diameter of NWs. Scale bar, $100 \mathrm{~nm}$ (white), $500 \mathrm{~nm}$ (black). Reprinted with permission from Ref. [1]. Copyright 2013, Springer Nature.
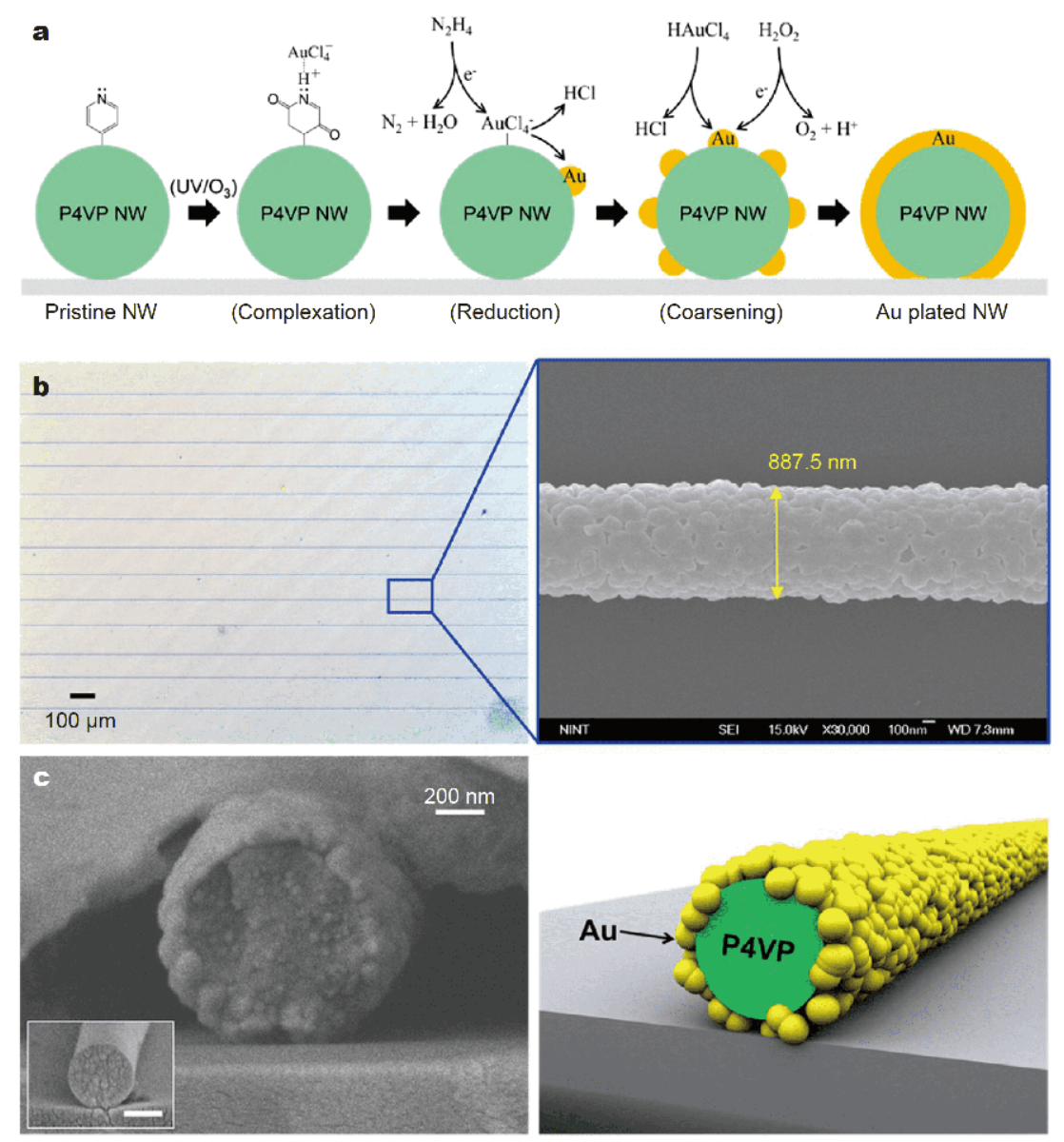

Figure 12 Electroless Au plating on a NW. (a) Schematic of electroless Au plating procedure on P4VP NW. (b) Parallel pattern of Au NW array with $100-\mu \mathrm{m}$ pitch. (c) SEM image (left) and schematic illustration (right) of a cross section of an electrolessly-plated Au NW (200 nm, scale bar). Reprinted with permission from Ref. [8]. Copyright 2017, American Chemical Society. 

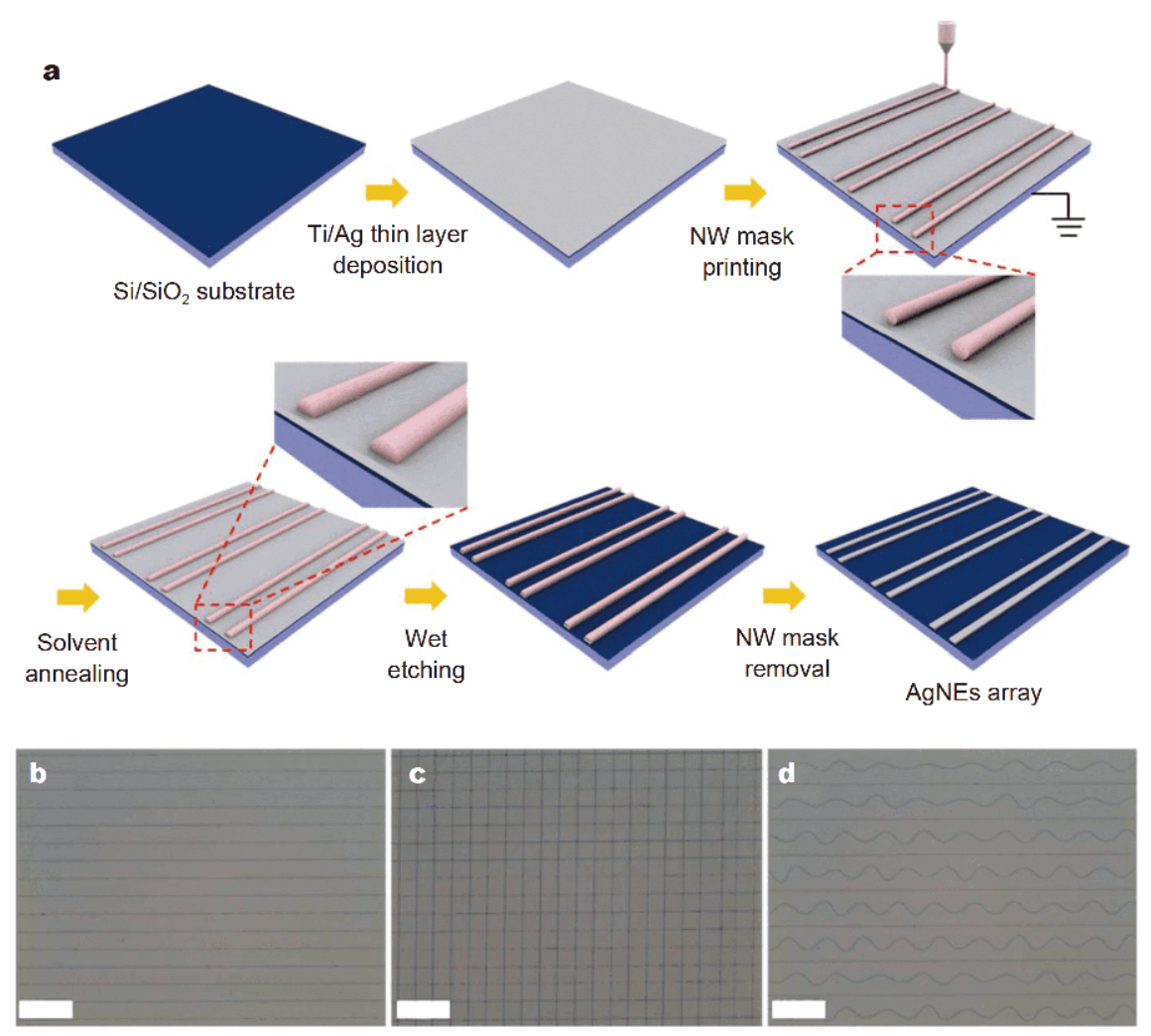

Figure 13 (a) Schematic illustration of the fabrication procedures of Ag NEs by printed NW lithography. SEM images of Ag NE arrays with various patterns: (b) parallel lines, (c) perpendicular grid lines, and (d) alternate straight and serpentine lines (scale bar: $300 \mu \mathrm{m}$ ). Reprinted with permission from Ref. [9]. Copyright 2017, The Royal Society of Chemistry.

Ag layer that were not protected by the NW masks. Finally, the NW masks were removed by washing with acetone. A uniformly-patterned, highly-conductive and large-scale Ag NE array was attained. Regardless of the width of the pattern, the resistivity of the Ag NE was consistent and lower than in previously-reported Ag NWs. e-NWP produces nano-scale silver NW arrays without the use of wet chemical etching.

\section{Synaptic transistor}

Synaptic transistors (STs) fabricated using e-NWP can emulate the morphology, working principles (e.g., shortterm plasticity, long-term potentiation, long-term depression) and energy consumption of synaptic junctions of nerve fibers [12] (Fig. 14). In the simulation of various synaptic behaviors, symmetry between enhancement and inhibition is the most important requirement (Fig. 14j, k). The current ONW device structure can simulate the storage capacity of synapses (Fig. 14l). The positive resistances accumulate continuously toward the conduction channel, leading to a significant increase in potential by using a series of positive resistances. The accumulation of the negative resistances also happens by using a series of negative resistance. The excitatory postsynaptic current (EPSC) of ONW device is related to the number of spikes (Fig. $14 \mathrm{~m}$ ). The process yielded transistors that had wellconfined 300-nm channel length. The NWs had a coresheath structure and were laid across a short nanochannel. The average energy consumption for each NW was $\sim 1.23 \mathrm{fJ}$ per spike which reached the energy consumption level of biological synapse (Fig. $14 \mathrm{~m}, \mathrm{n}$ ). A new method was demonstrated for the manufacture of nano-neuromorphic devices which was an important advance in the development of high density and low energy consumption electronic devices.

A stretchable ONW ST (s-ONWST) based on ionic gel gated FET was used to simulate the biological synapses in the sensorimotor nerve system [4] (Fig. 15a). Negative presynaptic voltage spikes gathered anions together near the surface of ONW; these anions aggregated on the surface of ONW and induced hole transport channels, and then generated EPSC with the required driving voltage. A single presynaptic stimulus $(-1 \mathrm{~V}, 120 \mathrm{~ms})$ induced an EPSC of $-6.43 \mathrm{nA}$, and due to the reverse 

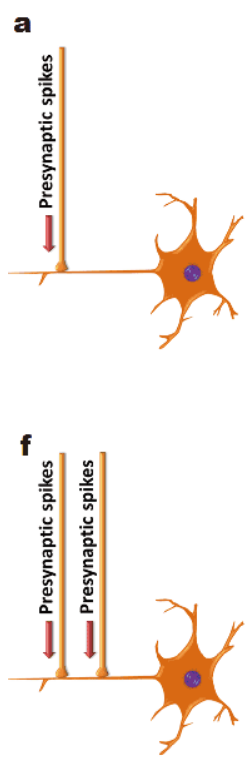

b
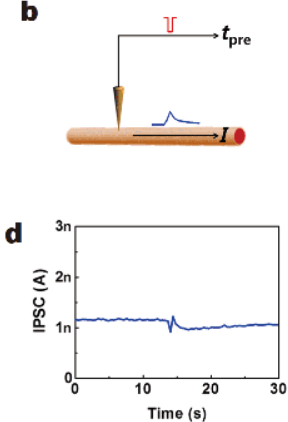

g
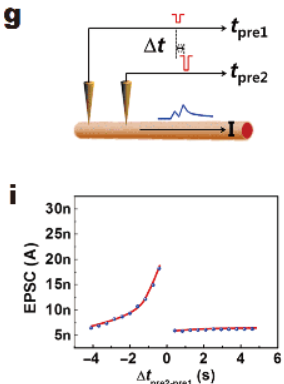

c
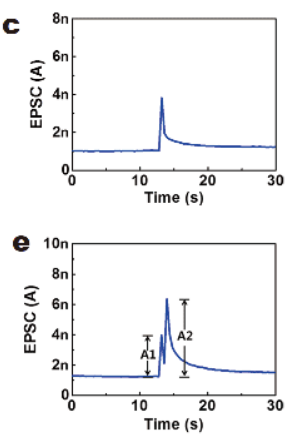

h

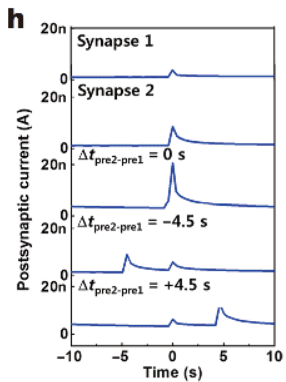

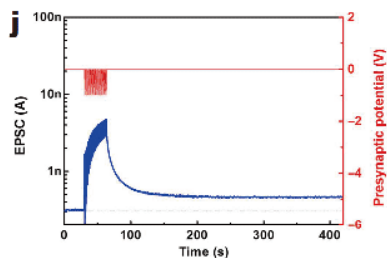
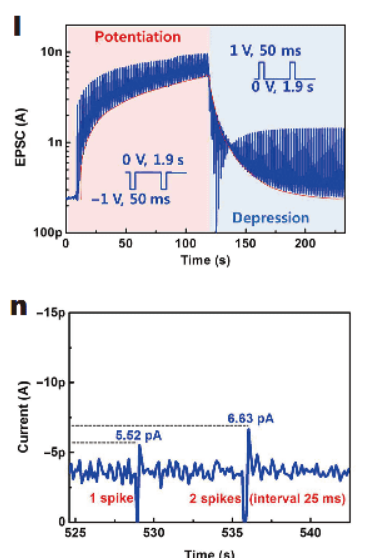

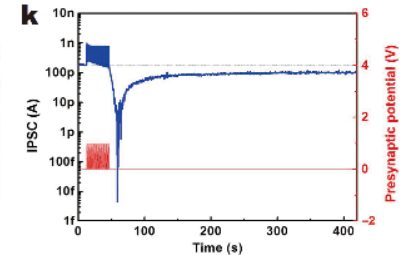

m
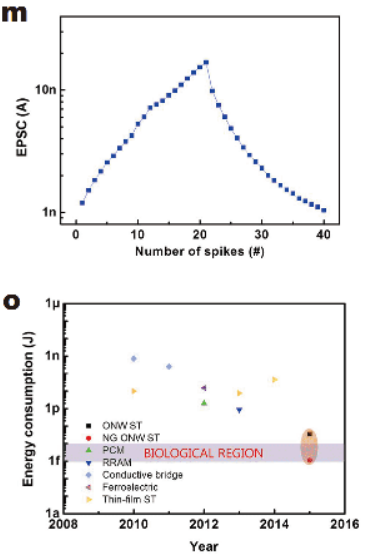

Figure 14 Process of (a) a presynaptic spike and (f) two presynaptic spikes to a postneuron and (b) a spatiotemporally correlated spike and (g) two spatiotemporally correlated spikes electrical pulses to an ONW ST that induces current responses through the ONW active channel. An EPSC of an ONW ST triggered by (c) a negative presynaptic spike and (e) two spikes. (d) Inhibitory postsynaptic current of an ONW ST triggered by a positive presynaptic spike. (h) EPSC of a single or pair of presynaptic spikes versus time. ( $\mathrm{j}-\mathrm{m}$ ) Long-term synaptic plasticity. (n) Short-term synaptic of a nano-gap ONW ST enhancement by two negative pulses. (o) Energy consumption per synaptic event of current available synaptic devices. Reprinted with permission from Ref. [12]. Copyright 2016, American Association for the Advancement of Science.

diffusion of the anion through the electrolyte, the EPSC decayed to a resting current of $I \approx-0.2 \mathrm{nA}$ in a matter of seconds (Fig. 15b). Paired pulse stimulation (PPF) produced by continuous pulses was separated by short interval $\Delta t$ to strengthen the postsynaptic signals, resulting in short-term synaptic enhancement. And the decrease of $\Delta t$ enhanced the postsynaptic current. For s-ONWST artificial synapses, the second peak value of EPSC $\left(A_{2}\right)$ reached 1.34 times of the first peak value of EPSC $\left(A_{1}\right)$ stimulated by a paired pulse of $\Delta t=120 \mathrm{~ms}$ (Fig. 15b). This phenomenon was due to the fact that the accumulated anions produced by the first pulse had not completely diffused before the accumulation of additional anions caused by the second pulse. Therefore, EPSC increased with the increase of accumulated anions near NW. With the increase of $\Delta t$, the number of anions accumulated from the first peak gradually dissipated, so PPF $\left(A_{2} / A_{1}\right)$ decreased. (Fig. $15 \mathrm{c}$ ). s-ONWST still possessed various synaptic properties under $100 \%$ tensile strain, such as PPF $\left(A_{2} / A_{1}\right)$, spike voltage-dependent plasticity (SVDP), spike number-dependent plasticity (SNDP), spike frequency-dependent plasticity (SFDP) and EPSC gain $\left(A_{10} / A_{1}\right)$. According to the applied presynaptic spike voltage $(-0.3$ to $-1 \mathrm{~V}$, increment is
$-0.1 \mathrm{~V}$ ), strengthen EPSC current from -1.96 to -6.66 $\mathrm{nA}$; the EPSC increase was obtained because of the adding voltage and the subsequently accumulative ion amount (Fig. 15d). As the number of presynaptic stimulates $n$ increased from 0 to 50, EPSC increased due to the accumulation of anions (Fig. 15e). In the s-ONWST, EPSC increased steadily with the increase of frequency of presynaptic spike $f_{\text {SPIKE }}$ (Fig. 15f). With the increase of $f_{\text {SPIKE }}$, EPSC gain $\left(A_{10} / A_{1}\right)$ strengthened from 1.07 to 1.55 slowly, in consistence with the dynamic high-pass filtering of signal transmission in synapses (Fig. 15g) [4]. In this work, the first neurologically-inspired organic optoelectronic sensorimotor synapse by e-NWP showed stable $I-V$ characteristics and various typical postsynaptic behaviors. An artificial muscle was actuated by the organic optoelectronic sensorimotor synapse with the biological muscle tension responses during contraction. This suggests that an artificial sensorimotor nervous system of soft electronics and neurorobotics can be fabricated using e-NWP.

\section{CONCLUSION AND PERSPECTIVE}

e-NWP to prepare NW materials has become an important academic and technical topic in the field of ma- 
a
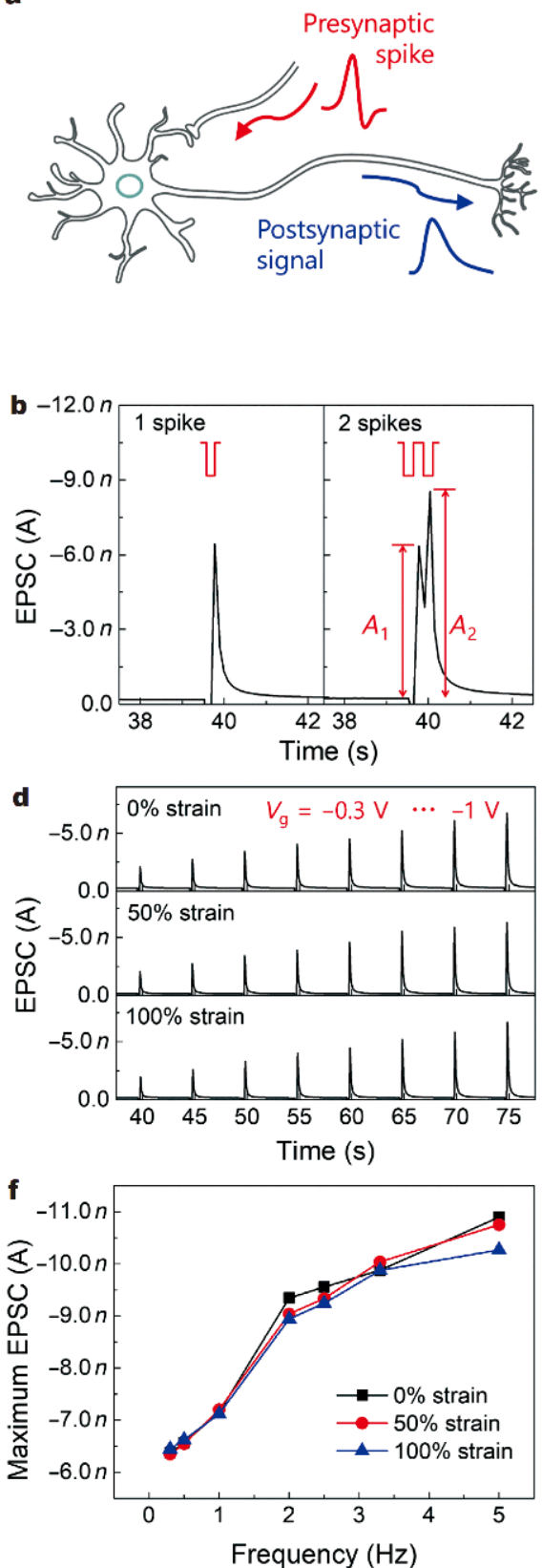
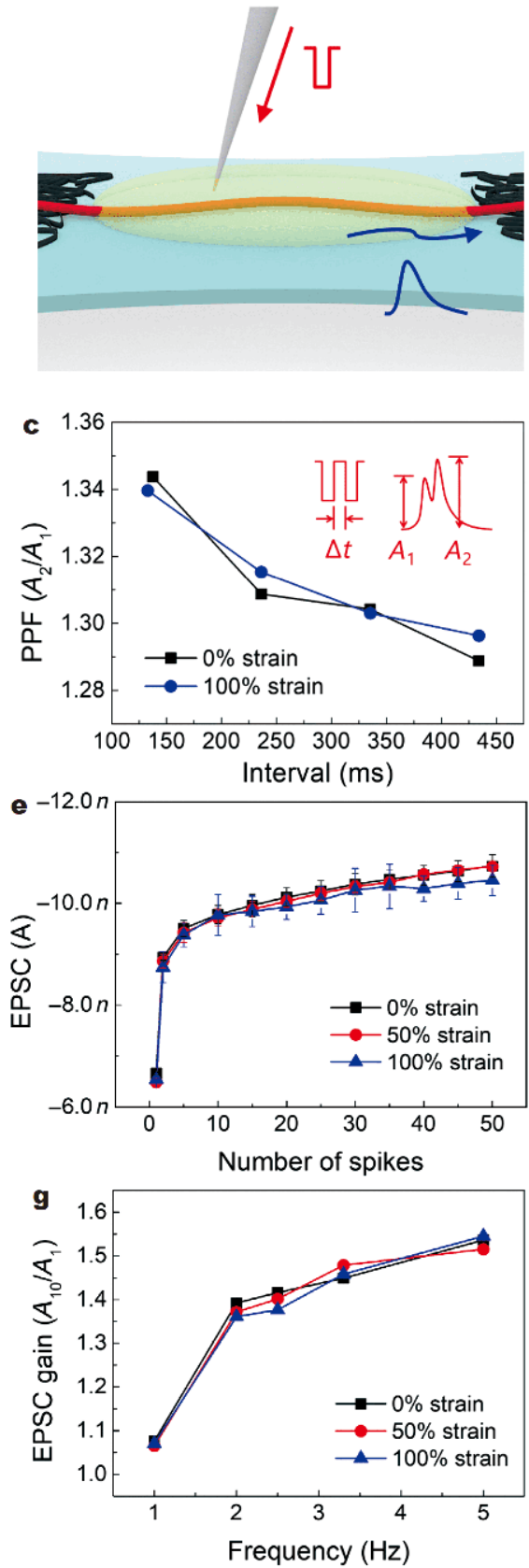

Figure 15 (a) Neural signal transmission from pre-neuron to postneuron through a biological synapse (left) and an artificial synapse (right). (b) EPSCs triggered by single and double spikes. $A_{1}$ and $A_{2}$ are EPSCs of the first and second spikes with an interval of 120 ms, respectively. (c-g) Postsynaptic characteristics of stretched artificial synapse from 0 to $100 \%$ strains; (c) the function between PPF $\left(A_{2} / A_{1}\right)$ and interval, (d) SVDP with various gate voltages, (e) SNDP. SFDP characteristics with spike frequency, (f) maximum EPSCs and (g) EPSC gain $\left(A_{10} / A_{1}\right)$ of stretched artificial synapse. Reprinted with permission from Ref. [4]. Copyright 2018, American Association for the Advancement of Science.

terials science and technology. e-NWP has advantageous properties such as simple manufacturing, low cost, and precision control, so the method has become an important technique for preparation of NWs materials. eNWP has been used to prepare a wide variety of NWs, including polymers, metal-oxide-doped and metal-doped NWs. However, the preparation of NWs by using e-NWP still has limitations.

First, e-NWP has demonstrated its feasibility in printing polymeric and metallic NWs using several re- 
presentative materials. These are just initial attempts, and the research field is still at its beginning stage. More functions can be potentially realized by this approach. For example, light, magnetic field, and thermal responsive materials can be blended into the NWs or directly printed into NWs to realize different functionalities. We can also use flexible stretchable materials, or biomedical materials to fabricate NWs for flexible electronics or biomedical applications.

Second, molecular structures of the source material and their nanoscale aggregation behaviors in NW could significantly influence the electrical or optical properties of the printed NWs. However, these correlations still require further investigation.

Furthermore, e-NWP has been feasible to print semiconductor lines, conductor lines, insulator lines, etc., and these components are essential for constructing integrated circuits. All-NW electronics can be expected using this technique for future applications such as wearable electronics.

NWs have potential applications in highly-integrated optoelectronic devices, microfluidic chips, soft bionics, flexible wearable electronic NWs textiles, software robots, biological monitoring, aerospace equipment, and other fields. Therefore, solving the above three scientific problems will promote the development of modern science and technology.

\section{Received 8 May 2019; accepted 13 August 2019;} published online 16 September 2019

1 Min SY, Kim TS, Kim BJ, et al. Large-scale organic nanowire lithography and electronics. Nat Commun, 2013, 4: 1773

2 Zeleny J. The electrical discharge from liquid points, and a hydrostatic method of measuring the electric intensity at their surfaces. Phys Rev, 1914, 3: 69-91

3 Formhals A. Process and apparatus for preparing artificial threads. US Patent Specification, 1934, 1975504

4 Lee Y, Oh JY, Xu W, et al. Stretchable organic optoelectronic sensorimotor synapse. Sci Adv, 2018, 4: eaat7387

5 Lee Y, Oh JY, Kim TR, et al. Deformable organic nanowire fieldeffect transistors. Adv Mater, 2018, 30: 1704401

6 Kim Y, Chortos A, Xu W, et al. A bioinspired flexible organic artificial afferent nerve. Science, 2018, 360: 998-1003

7 Chang J, He J, Lei Q, et al. Electrohydrodynamic printing of microscale PEDOT:PSS-PEO features with tunable conductive/ thermal properties. ACS Appl Mater Interfaces, 2018, 10: 1911619122

8 Min SY, Lee Y, Kim SH, et al. Room-temperature-processable wire-templated nanoelectrodes for flexible and transparent allwire electronics. ACS Nano, 2017, 11: 3681-3689

9 Ko HS, Lee Y, Min SY, et al. Large-scale metal nanoelectrode arrays based on printed nanowire lithography for nanowire complementary inverters. Nanoscale, 2017, 9: 15766-15772
10 Lee Y, Min SY, Kim TS, et al. Versatile metal nanowiring platform for large-scale nano- and opto-electronic devices. Adv Mater, 2016, 28: 9109-9116

11 Wang JC, Chang MW, Ahmad Z, et al. Fabrication of patterned polymer-antibiotic composite fibers via electrohydrodynamic (EHD) printing. J Drug Deliver Sci Tech, 2016, 35: 114-123

$12 \mathrm{Xu} \mathrm{W}$, Min SY, Hwang H, et al. Organic core-sheath nanowire artificial synapses with femtojoule energy consumption. Sci Adv, 2016, 2: e1501326

13 Cho H, Jeong SH, Min SY, et al. Scalable noninvasive organic fiber lithography for large-area optoelectronics. Adv Opt Mater, 2016, 4: 967-972

$14 \mathrm{Xu} \mathrm{W}$, Wang L, Liu Y, et al. Controllable n-type doping on CVDgrown single- and double-layer graphene mixture. Adv Mater, 2015, 27: 1619-1623

15 Min SY, Kim YH, Wolf C, et al. Synergistic effects of doping and thermal treatment on organic semiconducting nanowires. ACS Appl Mater Interfaces, 2015, 7: 18909-18914

$16 \mathrm{Xu} \mathrm{W,} \mathrm{Seo} \mathrm{HK,} \mathrm{Min} \mathrm{SY,} \mathrm{et} \mathrm{al.} \mathrm{Rapid} \mathrm{fabrication} \mathrm{of} \mathrm{designable}$ large-scale aligned graphene nanoribbons by electro-hydrodynamic nanowire lithography. Adv Mater, 2014, 26: 3459-3464

17 Lee H, Seong B, Kim J, et al. Direct alignment and patterning of silver nanowires by electrohydrodynamic jet printing. Small, 2014, 10: 3918-3922

18 Hwang SK, Min SY, Bae I, et al. Non-volatile ferroelectric memory with position-addressable polymer semiconducting nanowire. Small, 2014, 10: 1976-1984

$19 \mathrm{Xu} \mathrm{W,} \mathrm{Lim} \mathrm{TS,} \mathrm{Seo} \mathrm{HK,} \mathrm{et} \mathrm{al.} \mathrm{N-doped} \mathrm{graphene} \mathrm{field-effect}$ transistors with enhanced electron mobility and air-stability. Small, 2014, 10: 1999-2005

20 Lee Y, Kim TS, Min SY, et al. Individually position-addressable metal-nanofiber electrodes for large-area electronics. Adv Mater, 2014, 26: 8010-8016

21 Kress SJP, Richner P, Jayanti SV, et al. Near-field light design with colloidal quantum dots for photonics and plasmonics. Nano Lett, 2014, 14: 5827-5833

22 Jeong YJ, Lee H, Lee BS, et al. Directly drawn poly(3hexylthiophene) field-effect transistors by electrohydrodynamic jet printing: improving performance with surface modification. ACS Appl Mater Interfaces, 2014, 6: 10736-10743

23 Wang Z, Chen X, Zeng J, et al. Controllable deposition distance of aligned pattern via dual-nozzle near-field electrospinning. AIP Adv, 2017, 7: 035310

24 Vidyadharan B, Misnon II, Ismail J, et al. High performance asymmetric supercapacitors using electrospun copper oxide nanowires anode. J Alloys Compd, 2015, 633: 22-30

25 Zheng Y, Cheng L, Yuan M, et al. An electrospun nanowire-based triboelectric nanogenerator and its application in a fully selfpowered UV detector. Nanoscale, 2014, 6: 7842-7846

26 Vidyadharan B, Aziz RA, Misnon II, et al. High energy and power density asymmetric supercapacitors using electrospun cobalt oxide nanowire anode. J Power Sources, 2014, 270: 526-535

27 Vidhyadharan B, Misnon II, Aziz RA, et al. Superior supercapacitive performance in electrospun copper oxide nanowire electrodes. J Mater Chem A, 2014, 2: 6578-6588

28 Hsu PC, Kong D, Wang S, et al. Electrolessly deposited electrospun metal nanowire transparent electrodes. J Am Chem Soc, 2014, 136: 10593-10596

29 Higgins DC, Wang R, Hoque MA, et al. Morphology and composition controlled platinum-cobalt alloy nanowires prepared by 
electrospinning as oxygen reduction catalyst. Nano Energy, 2014, 10: $135-143$

30 Hsu PC, Wang S, Wu H, et al. Performance enhancement of metal nanowire transparent conducting electrodes by mesoscale metal wires. Nat Commun, 2013, 4: 2522

31 Zhang CL, Lv KP, Huang HT, et al. Co-assembly of Au nanorods with $\mathrm{Ag}$ nanowires within polymer nanofiber matrix for enhanced SERS property by electrospinning. Nanoscale, 2012, 4: 5348-5355

$32 \mathrm{Wu} \mathrm{W}$, Bai S, Yuan $\mathrm{M}$, et al. Lead zirconate titanate nanowire textile nanogenerator for wearable energy-harvesting and selfpowered devices. ACS Nano, 2012, 6: 6231-6235

33 Wu H, Pan W, Lin D, et al. Electrospinning of ceramic nanofibers: Fabrication, assembly and applications. J Adv Ceram, 2012, 1: $2-23$

34 Krishnamoorthy T, Tang MZ, Verma A, et al. A facile route to vertically aligned electrospun $\mathrm{SnO}_{2}$ nanowires on a transparent conducting oxide substrate for dye-sensitized solar cells. J Mater Chem, 2012, 22: 2166-2172

35 Arras MML, Grasl C, Bergmeister H, et al. Electrospinning of aligned fibers with adjustable orientation using auxiliary electrodes. Sci Tech Adv Mater, 2012, 13: 035008

36 Zhu C, Yu Y, Gu L, et al. Electrospinning of highly electroactive carbon-coated single-crystalline $\mathrm{LiFePO}_{4}$ nanowires. Angew Chem Int Ed, 2011, 50: 6278-6282

37 Zhang P, Guo ZP, Huang Y, et al. Synthesis of $\mathrm{Co}_{3} \mathrm{O}_{4} /$ carbon composite nanowires and their electrochemical properties. J Power Sources, 2011, 196: 6987-6991

38 Song J, Chen M, Olesen MB, et al. Direct electrospinning of Ag/ polyvinylpyrrolidone nanocables. Nanoscale, 2011, 3: 4966-4971

39 Lee JS, Lee YI, Song H, et al. Synthesis and characterization of $\mathrm{TiO}_{2}$ nanowires with controlled porosity and microstructure using electrospinning method. Curr Appl Phys, 2011, 11: S210S214

40 Krishnamoorthy T, Thavasi V, Subodh G M, et al. A first report on the fabrication of vertically aligned anatase $\mathrm{TiO}_{2}$ nanowires by electrospinning: Preferred architecture for nanostructured solar cells. Energy Environ Sci, 2011, 4: 2807

41 Hou Z, Cheng Z, Li G, et al. Electrospinning-derived $\mathrm{Tb}_{2}\left(\mathrm{WO}_{4}\right)_{3}$ : $\mathrm{Eu}^{3+}$ nanowires: energy transfer and tunable luminescence properties. Nanoscale, 2011, 3: 1568-1574

42 Xu L, Dong B, Wang Y, et al. Electrospinning preparation and room temperature gas sensing properties of porous $\operatorname{In}_{2} \mathrm{O}_{3}$ nanotubes and nanowires. Sensor Actuat B-Chem, 2010, 147: 531-538

43 Wu Y, Dong Z, Wilson S, et al. Template-assisted assembly of electrospun fibers. Polymer, 2010, 51: 3244-3248

44 Nguyen TH, Lee KH, Lee BT. Fabrication of Ag nanoparticles dispersed in PVA nanowire mats by microwave irradiation and electro-spinning. Mater Sci Eng-C, 2010, 30: 944-950

45 Mai L, Xu L, Han C, et al. Electrospun ultralong hierarchical vanadium oxide nanowires with high performance for lithium ion batteries. Nano Lett, 2010, 10: 4750-4755

46 Kim JM, Joh HI, Jo SM, et al. Preparation and characterization of Pt nanowire by electrospinning method for methanol oxidation. Electrochim Acta, 2010, 55: 4827-4835

47 Hosono E, Wang Y, Kida N, et al. Synthesis of triaxial $\mathrm{LiFePO}_{4}$ nanowire with a VGCF core column and a carbon shell through the electrospinning method. ACS Appl Mater Interfaces, 2010, 2: 212-218

48 Cui X, Li L, Xu F. Controlled assembly of poly(vinyl pyrrolidone) fibers through an electric-field-assisted electrospinning method. Appl Phys A, 2010, 103: 167-172

49 Chen H, Wang N, Di J, et al. Nanowire-in-microtube structured core/shell fibers via multifluidic coaxial electrospinning. Langmuir, 2010, 26: 11291-11296

50 Archana PS, Jose R, Jin TM, et al. Structural and electrical properties of $\mathrm{Nb}$-doped anatase $\mathrm{TiO}_{2}$ nanowires by electrospinning. J Am Ceramic Soc, 2010, 93: 4096-4102

$51 \mathrm{Xu} \mathrm{L}$, Song H, Dong B, et al. Electrospinning preparation and photoluminescence properties of lanthanum phosphate nanowires and nanotubes. J Phys Chem C, 2009, 113: 9609-9615

52 Wu WY, Ting JM, Huang PJ. Electrospun $\mathrm{ZnO}$ nanowires as gas sensors for ethanol detection. Nanoscale Res Lett, 2009, 4: 513517

$53 \mathrm{Wu} \mathrm{H}$, Sun Y, Lin D, et al. GaN nanofibers based on electrospinning: facile synthesis, controlled assembly, precise doping, and application as high performance UV photodetector. Adv Mater, 2009, 21: 227-231

54 Shui J, Li JCM. Platinum nanowires produced by electrospinning. Nano Lett, 2009, 9: 1307-1314

55 Shim HS, Kim JW, Sung YE, et al. Electrochromic properties of tungsten oxide nanowires fabricated by electrospinning method. Sol Energy Mater Sol Cells, 2009, 93: 2062-2068

56 Kim HJ, Kim YS, Seo MH, et al. Pt and PtRh nanowire electrocatalysts for cyclohexane-fueled polymer electrolyte membrane fuel cell. Electrochem Commun, 2009, 11: 446-449

57 Hou Z, Li C, Yang J, et al. One-dimensional $\mathrm{CaWO}_{4}$ and $\mathrm{CaWO}_{4}$ : $\mathrm{Tb}^{3+}$ nanowires and nanotubes: electrospinning preparation and luminescent properties. J Mater Chem, 2009, 19: 2737

58 Archana PS, Jose R, Vijila C, et al. Improved electron diffusion coefficient in electrospun $\mathrm{TiO}_{2}$ nanowires. J Phys Chem C, 2009, 113: 21538-21542

$59 \mathrm{Wu} \mathrm{H}$, Lin D, Zhang R, et al. ZnO nanofiber field-effect transistor assembled by electrospinning. J Am Ceramic Soc, 2008, 91: 656659

60 Song $\mathrm{H}, \mathrm{Yu} \mathrm{HQ}$, Pan G, et al. Electrospinning preparation, structure, and photoluminescence properties of $\mathrm{YBO}_{3}: \mathrm{Eu}^{3+}$ nanotubes and nanowires. Chem Mater, 2008, 20: 4762-4767

61 Shim HS, Na SI, Nam SH, et al. Efficient photovoltaic device fashioned of highly aligned multilayers of electrospun $\mathrm{TiO}_{2}$ nanowire array with conjugated polymer. Appl Phys Lett, 2008, 92: 183107

62 Pan $\mathrm{C}, \mathrm{Wu} \mathrm{H}$, Wang C, et al. Nanowire-based high-performance "micro fuel cells": one nanowire, one fuel cell. Adv Mater, 2008, 20: $1644-1648$

63 Kim YS, Nam SH, Shim HS, et al. Electrospun bimetallic nanowires of PtRh and PtRu with compositional variation for methanol electrooxidation. Electrochem Commun, 2008, 10: 10161019

64 Formo E, Lee E, Campbell D, et al. Functionalization of electrospun $\mathrm{TiO}_{2}$ nanofibers with Pt nanoparticles and nanowires for catalytic applications. Nano Lett, 2008, 8: 668-672

65 Feenstra J, Sodano HA. Enhanced active piezoelectric 0-3 nanocomposites fabricated through electrospun nanowires. J Appl Phys, 2008, 103: 124108

66 Attout A, Yunus S, Bertrand P. Electrospinning and alignment of polyaniline-based nanowires and nanotubes. Polym Eng Sci, 2008, 48: 1661-1666

67 Lin D, Wu H, Pan W. Photoswitches and memories assembled by electrospinning aluminum-doped zinc oxide single nanowires. 
Adv Mater, 2007, 19: 3968-3972

68 Lin D, Wu H, Zhang R, et al. Preparation and electrical properties of electrospun tin-doped indium oxide nanowires. Nanotechnology, 2007, 18: 465301

69 Sawicka KM, Gouma P. Electrospun composite nanofibers for functional applications. J Nanopart Res, 2006, 8: 769-781

70 Kim ID, Rothschild A, Lee BH, et al. Ultrasensitive chemiresistors based on electrospun $\mathrm{TiO}_{2}$ nanofibers. Nano Lett, 2006, 6: 20092013

71 Hong KH, Kang TJ. Polyaniline-nylon 6 composite nanowires prepared by emulsion polymerization and electrospinning process. J Appl Polym Sci, 2006, 99: 1277-1286

72 Ding B, Li C, Miyauchi Y, et al. Formation of novel 2D polymer nanowebs via electrospinning. Nanotechnology, 2006, 17: 36853691

73 Ye H, Titchenal N, Gogotsi Y, et al. SiC nanowires synthesized from electrospun nanofiber templates. Adv Mater, 2005, 17: 1531-1535

74 Reneker DH, Chun I. Nanometre diameter fibres of polymer, produced by electrospinning. Nanotechnology, 1996, 7: 216-223

75 Kameoka J, Craighead HG. Fabrication of oriented polymeric nanofibers on planar surfaces by electrospinning. Appl Phys Lett, 2003, 83: 371-373

76 Liu H, Reccius CH, Craighead HG. Single electrospun regioregular poly(3-hexylthiophene) nanofiber field-effect transistor. Appl Phys Lett, 2005, 87: 253106

77 Bellan LM, Craighead HG. Control of an electrospinning jet using electric focusing and jet-steering fields. J Vac Sci Technol B, 2006, 24: 3179

78 Sun D, Chang C, Li S, et al. Near-field electrospinning. Nano Lett, 2006, 6: 839-842

79 Lee S, Limkrailassiri K, Gao Y, Chang C, Lin LW. Chip-to-chip fluidic connectors via near-field electrospinning. Proceedings of the IEEE Twentieth Annual International Conference, on Micro Electro Mechanical Systems, 2007, 1-2: 252

80 Chang C, Limkrailassiri K, Lin L. Continuous near-field electrospinning for large area deposition of orderly nanofiber patterns. Appl Phys Lett, 2008, 93: 123111

81 Yang Y, Jia Z, Liu J, et al. Effect of electric field distribution uniformity on electrospinning. J Appl Phys, 2008, 103: 104307

82 Zhang $\mathrm{Y}, \mathrm{He} \mathrm{X}, \mathrm{Li}$ J, et al. Fabrication and ethanol-sensing properties of micro gas sensor based on electrospun $\mathrm{SnO}_{2}$ nanofibers. Sensor Actuat B-Chem, 2008, 132: 67-73

83 Ding Z, Salim A, Ziaie B. Selective nanofiber deposition through field-enhanced electrospinning. Langmuir, 2009, 25: 9648-9652

84 Rinaldi M, Ruggieri F, Lozzi L, et al. Well-aligned $\mathrm{TiO}_{2}$ nanofibers grown by near-field-electrospinning. J Vac Sci Technol B, 2009, 27: 1829

85 Fuh YK, Hsu HS. Controlled formation of multiple jets and nanofibers deposition via near-field electrospinning process. Int J Nonlinear Sci Numer Simul, 2010, 11

$86 \mathrm{Pu}$ J, Yan X, Jiang Y, et al. Piezoelectric actuation of direct-write electrospun fibers. Sensor Actuat A-Phys, 2010, 164: 131-136

87 Zheng G, Li W, Wang X, et al. Precision deposition of a nanofibre by near-field electrospinning. J Phys D-Appl Phys, 2010, 43: 415501

88 Bisht GS, Canton G, Mirsepassi A, et al. Controlled continuous patterning of polymeric nanofibers on three-dimensional substrates using low-voltage near-field electrospinning. Nano Lett, 2011, 11: 1831-1837
89 Chen D, Lei S, Chen Y. A single polyaniline nanofiber field effect transistor and its gas sensing mechanisms. Sensors, 2011, 11: 6509-6516

90 Fang J, Wang X, Lin T. Electrical power generator from randomly oriented electrospun poly(vinylidene fluoride) nanofibre membranes. J Mater Chem, 2011, 21: 11088

91 Padmanabhan T, Kamaraj V, Magwood Jr. L, et al. Experimental investigation on the operating variables of a near-field electrospinning process via response surface methodology. J Manufact Proc, 2011, 13: 104-112

92 Zhou FL, Hubbard PL, Eichhorn SJ, et al. Jet deposition in nearfield electrospinning of patterned polycaprolactone and sugarpolycaprolactone core-shell fibres. Polymer, 2011, 52: 3603-3610

93 Bisht G, Nesterenko S, Kulinsky L, et al. A computer-controlled near-field electrospinning setup and its graphic user interface for precision patterning of functional nanofibers on $2 \mathrm{D}$ and $3 \mathrm{D}$ substrates. J Lab Autom, 2012, 17: 302-308

94 Fuh YK, Chen S, Jang JSC. Direct-write, well-aligned chitosanpoly(ethylene oxide) nanofibers deposited via near-field electrospinning. J MacroMol Sci Part A, 2012, 49: 845-850

95 Huang YYS, Terentjev EM, Oppenheim T, et al. Fabrication and electromechanical characterization of near-field electrospun composite fibers. Nanotechnology, 2012, 23: 105305

96 Wang X, Zheng G, Xu L, et al. Fabrication of nanochannels via near-field electrospinning. Appl Phys A, 2012, 108: 825-828

97 Zheng J, Long YZ, Sun B, et al. Polymer nanofibers prepared by low-voltage near-field electrospinning. Chin Phys B, 2012, 21: 048102

98 Biagi G, Holmgaard T, Skovsen E. Near-field electrospinning of dielectric-loaded surface plasmon polariton waveguides. Opt Express, 2013, 21: 4355-4360

99 Di Camillo D, Fasano V, Ruggieri F, et al. Near-field electrospinning of light-emitting conjugated polymer nanofibers. Nanoscale, 2013, 5: 11637-11642

100 Fuh YK, Chen SY, Ye JC. Massively parallel aligned microfibersbased harvester deposited via in situ, oriented poled near-field electrospinning. Appl Phys Lett, 2013, 103: 033114

101 Liu ZH, Pan CT, Lin LW, et al. Piezoelectric properties of PVDF/ MWCNT nanofiber using near-field electrospinning. Sensor Actuat A-Phys, 2013, 193: 13-24

102 Ruggieri F, Di Camillo D, Lozzi L, et al. Preparation of nitrogen doped $\mathrm{TiO}_{2}$ nanofibers by near field electrospinning (NFES) technique for $\mathrm{NO}_{2}$ sensing. Sensor Actuat B-Chem, 2013, 179: 107-113

103 Chang J, Liu Y, Heo K, et al. Direct-write complementary graphene field effect transistors and junctions via near-field electrospinning. Small, 2014, 10: 1920-1925

104 Liu ZH, Pan CT, Lin LW, Huang JC, Ou ZY. Direct-write PVDF nonwoven fiber fabric energy harvesters via the hollow cylindrical near-field electrospinning process. Smart Mater Struct, 2014, 23: 025003

105 Pan CT, Yen CK, Lin L, et al. Energy harvesting with piezoelectric $\operatorname{poly}(\gamma$-benzyl- $L$-glutamate) fibers prepared through cylindrical near-field electrospinning. RSC Adv, 2014, 4: 21563

$106 \mathrm{Ru} \mathrm{C}$, Chen J, Shao Z, et al. A novel mathematical model for controllable near-field electrospinning. AIP Adv, 2014, 4: 017108

107 Han W, Minhao L, Xin C, et al. Study of deposition characteristics of multi-nozzle near-field electrospinning in electric field crossover interference conditions. AIP Adv, 2015, 5: 041302

108 Lei TP, Lu XZ, Yang F. Fabrication of various micro/nano 
structures by modified near-field electrospinning. AIP Adv, 2015, 5: 041301

109 Pan CT, Yang TL, Chen YC, et al. Fibers and conductive films using silver nanoparticles and nanowires by near-field electrospinning process. J Nanomater, 2015, 2015: 1-5

110 Pan CT, Yen CK, Wang SY, et al. Near-field electrospinning enhances the energy harvesting of hollow PVDF piezoelectric fibers. RSC Adv, 2015, 5: 85073-85081

111 Pan CT, Yen CK, Wu HC, et al. Significant piezoelectric and energy harvesting enhancement of poly(vinylidene fluoride)/ polypeptide fiber composites prepared through near-field electrospinning. J Mater Chem A, 2015, 3: 6835-6843

112 Yang TL, Pan CT, Chen YC, et al. Synthesis and fabrication of silver nanowires embedded in PVP fibers by near-field electrospinning process. Optical Mater, 2015, 39: 118-124

113 Fuh YK, Wang BS. Near field sequentially electrospun three-dimensional piezoelectric fibers arrays for self-powered sensors of human gesture recognition. Nano Energy, 2016, 30: 677-683

114 Fuh YK, Wu YC, He ZY, et al. The control of cell orientation using biodegradable alginate fibers fabricated by near-field electrospinning. Mater Sci Eng-C, 2016, 62: 879-887

115 He XX, Zheng J, Yu GF, et al. Near-field electrospinning: progress and applications. J Phys Chem C, 2017, 121: 8663-8678

116 He FL, Li DW, He J, et al. A novel layer-structured scaffold with large pore sizes suitable for 3D cell culture prepared by near-field electrospinning. Mater Sci Eng-C, 2018, 86: 18-27

117 Sarkar J, Khan GG, Basumallick A. Nanowires: properties, applications and synthesis via porous anodic aluminium oxide template. Bull Mater Sci, 2007, 30: 271-290

118 Meng S, Ren J, Kaxiras E. Natural dyes adsorbed on $\mathrm{TiO}_{2}$ nanowire for photovoltaic applications: enhanced light absorption and ultrafast electron injection. Nano Lett, 2008, 8: 3266-3272

119 Muskens OL, Rivas JG, Algra RE, et al. Design of light scattering in nanowire materials for photovoltaic applications. Nano Lett, 2008, 8: 2638-2642

120 Singh N, Buddharaju KD, Manhas SK, et al. Si, SiGe nanowire devices by top-down technology and their applications. IEEE Trans Electron Devices, 2008, 55: 3107-3118

121 Carmo M, Sekol RC, Ding S, et al. Bulk metallic glass nanowire architecture for electrochemical applications. ACS Nano, 2011, 5: 2979-2983

122 Krantz J, Richter M, Spallek S, et al. Solution-processed metallic nanowire electrodes as indium tin oxide replacement for thinfilm solar cells. Adv Funct Mater, 2011, 21: 4784-4787

123 Poellmann MJ, Barton KL, Mishra S, et al. Patterned hydrogel substrates for cell culture with electrohydrodynamic jet printing. Macromol Biosci, 2011, 11: 1164-1168

124 Wang X, Xu L, Zheng GF, et al. Pulsed electrohydrodynamic printing of conductive silver patterns on demand. Sci China Technol Sci, 2012, 55: 1603-1607

125 Zhang Y, Ram MK, Stefanakos EK, et al. Synthesis, characterization, and applications of $\mathrm{ZnO}$ nanowires. J Nanomater, 2012, 2012: 1-22

126 Hashimdeen SH, Miodownik M, Edirisinghe MJ. Print head design and control for electrohydrodynamic printing of silk fibroin. Mater Sci Eng-C, 2013, 33: 3309-3318

127 Dasgupta NP, Sun J, Liu C, et al. Semiconductor nanowiressynthesis, characterization, and applications. Adv Mater, 2014, 26: 2137-2184

128 Han Y, Wei C, Dong J. Super-resolution electrohydrodynamic
(EHD) 3D printing of micro-structures using phase-change inks. Manufacturing Lett, 2014, 2: 96-99

129 Poellmann MJ, Wagoner Johnson AJ. Multimaterial polyacrylamide: fabrication with electrohydrodynamic jet printing, applications, and modeling. Biofabrication, 2014, 6: 035018

130 Song C, Rogers JA, Kim JM, et al. Patterned polydiacetyleneembedded polystyrene nanofibers based on electrohydrodynamic jet printing. Macromol Res, 2014, 23: 118-123

131 Teguh Yudistira H, Pradhipta Tenggara A, Oh SS, et al. Highresolution electrohydrodynamic jet printing for the direct fabrication of 3D multilayer terahertz metamaterial of high refractive index. J Micromech Microeng, 2015, 25: 045006

132 Kim SY, Kim K, Hwang YH, et al. High-resolution electrohydrodynamic inkjet printing of stretchable metal oxide semiconductor transistors with high performance. Nanoscale, 2016, 8: 17113-17121

133 Sannicolo T, Lagrange M, Cabos A, et al. Metallic nanowire-based transparent electrodes for next generation flexible devices: a review. Small, 2016, 12: 6052-6075

134 Makaev AV, Mingaliev EA, Karpov VR, et al. High-speed precise cell patterning by pulsed electrohydrodynamic jet printing. IOP Conference Series: Materials Science and Engineering, 2017, 256: 012013

135 Pan Y, Chen X, Zeng L, et al. Fabrication and evaluation of a protruding Si-based printhead for electrohydrodynamic jet printing. J Micromech Microeng, 2017, 27: 125004

136 Pradhipta Tenggara A, Park SJ, Teguh Yudistira H, et al. Fabrication of terahertz metamaterials using electrohydrodynamic jet printing for sensitive detection of yeast. J Micromech Microeng, 2017, 27: 035009

$137 \mathrm{Xu} \mathrm{Z}$, Zou H, Wang J, et al. Fabrication of electrochemical carbon-based microelectrodes using electrohydrodynamic jet printing technique. Microsyst Technol, 2017, 24: 1207-1212

138 Jiang J, Zheng G, Wang X, et al. Printing of highly conductive solution by alternating current electrohydrodynamic direct-write. J Phys-Conf Ser, 2018, 986: 012027

139 Kim JH, Park JW. Novel patterning method for nanomaterials and its application to flexible organic light-emitting diodes. ACS Appl Mater Interfaces, 2018, 10: 9704-9717

140 Li X, Jeong YJ, Jang J, et al. The effect of surfactants on electrohydrodynamic jet printing and the performance of organic field-effect transistors. Phys Chem Chem Phys, 2018, 20: 12101220

141 Oh SY, Hong SY, Jeong YR, et al. Skin-attachable, stretchable electrochemical sweat sensor for glucose and $\mathrm{pH}$ detection. ACS Appl Mater Interfaces, 2018, 10: 13729-13740

142 Sun C, Yang M, Wang T, et al. Stable and reversible lithium storage with high pseudocapacitance in GaN nanowires. ACS Appl Mater Interfaces, 2018, 10: 2574-2580

143 Wang D, Zhao X, Lin Y, et al. Nanoscale coaxial focused electrohydrodynamic jet printing. Nanoscale, 2018, 10: 9867-9879

144 Wang J, Yin Z. SU-8 nano-nozzle fabrication for electrohydrodynamic jet printing using UV photolithography. Mater Sci Semicond Proc, 2018, 84: 144-150

Acknowledgements This research was supported by the Brain Science and Brain-Like Intelligence Technology project of Guangdong (2018B030338001), the Hundred Young Academic Leaders Program of Nankai University, the Natural Science Foundation of Tianjin (18JCYBJC16000), the 111 Project (B16027), the International Co- 
operation Base (2016D01025), China Postdoctoral Science Foundation (2017M622432), the Postdoctoral Science and Technology Project of Hubei province, China (z12) and Tianjin International Joint Research and Development Center.

Author contributions $\mathrm{Xu}$ WT conceived the study and designed the structure of the manuscript. Xu WL participated in the writing of the "Introduction", "Mechanism" and "discussion" sections of the manuscript; Zhang S participated in the writing of "Different types NWs as obtained from e-NWP" and "Applications of e-NWP printed" section in manuscript.

Conflict of interest The authors declare that they have no conflict of interest.

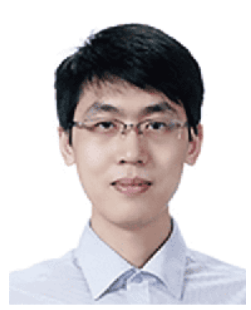

Wenlong Xu obtained his $\mathrm{PhD}$ at the Nanomaterial Chemistry Laboratory, Kyungpook National University (KNU) in 2014. He is currently a postdoctor at the Institute of Photoelectronic Thin Film Devices and Technology of Nankai University, China. His research project is on neuromorphic electronic devices, electrohydrodynamic nanowire printing and flexible electronics.

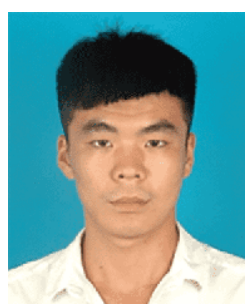

Shuo Zhang obtained his Master's degree at the State Key Laboratory of Metastable Materials Science and Technology, Yanshan University (YSU) in 2016. He is currently a $\mathrm{PhD}$ candidate at the Institute of Optoelectronic Thin Film Devices and Technology, Nankai University, China. His research project is on artificial synapse devices, organic nanowire printing and flexible electronics.

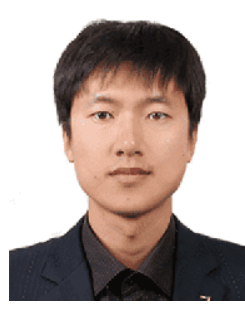

Wentao $\mathrm{Xu}$ is a professor at the Institute of Photoelectronic Thin Film Devices and Technology of Nankai University. He received his BSc degree at Beijing Normal University and his PhD at Pohang University of Science and Technology (POSTECH). He was also a research associate professor at Seoul National University (SNU) and visiting scholar at Stanford University and the University of Illinois at Urbana-Champaign. His research interests include neuromorphic electronic devices, flexible electronics, electrohydrodynamic nanowire printing, memory devices, and thin film transistors.

\section{数码可控纳米线打印的最新进展}

徐雯龙 ${ }^{\dagger}$, 张硕 $^{\dagger}$, 徐文涛 ${ }^{*}$

摘要 数码可控纳米线打印(e-NWP)技术可用于制备高精度印刷 图案化的纳米线. 该技术将有望促进大面积图案化纳米线阵列、 高精度和高集成度器件、纳米机电系统和生物启发器件等领域的 发展. e-NWP打印器件的电学特性可以通过控制纳米线的间隙和 直径来调节。这种技术已被应用于场效应晶体管、神经拟态器件 和掩模板等. 本综述总结了 e-NWP的基本原理、材料选择、打印 方法和应用尝试, 并展望了在拓展e-NWP应用和商业化进程中仍 需解决的问题. 